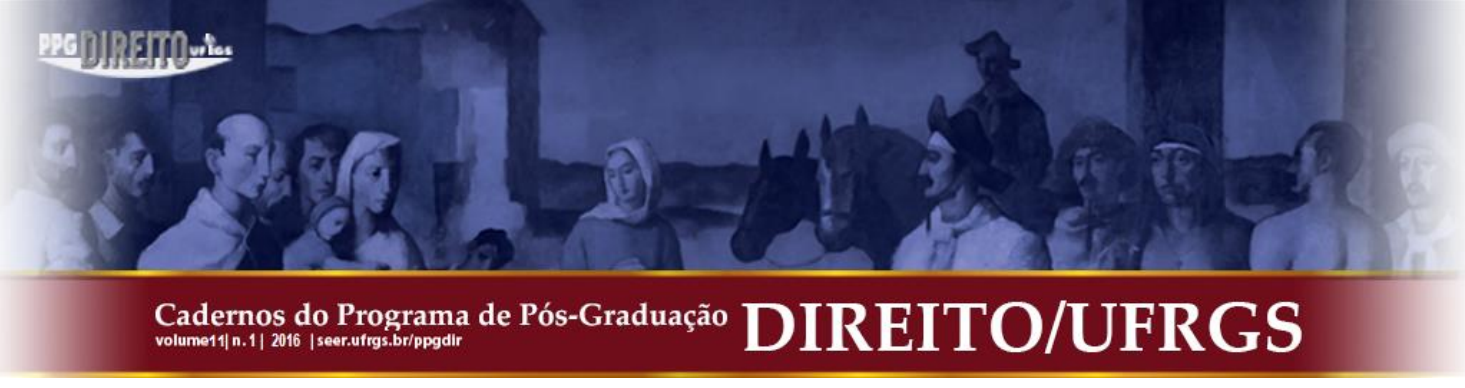

\title{
"L'ÉTAT, C'EST LE DROIT!« - SOBRE A ATUALIDADE DA TEORIA DO ESTADO DE HANS KELSEN EM FACE DA METAMORFOSE DO PODER ESTATAL *
}

\author{
»L'ÉTAT, C'EST LE DROIT!« - ZUR AKTUALITÄT DER STAATSLEHRE HANS KELSENS \\ IM ANGESICHT SICH WANDELNDER STAATSGEWALT
}

\author{
»L'ÉTAT, C'EST LE DROIT!« - THE CURRENT IMPORTANCE OF HANS KELSEN'S
}

STATE DOCTRINE IN LIGHT OF THE STATE POWER CHANGES

Philipp Reimer**

\begin{abstract}
RESUMO: Confrontada com evidentes mutações na estruturação de instituições e atividades estatais, a teoria do direito pode nos dizer que aspectos deste processo de metamorfose devem ser considerados pelos estudos jurídicos - bem como quais aspectos não precisam ser levados em conta. Fazendo uso de uma abordagem kelseniana, este artigo demonstra como a teoria do direito (compreendida como disciplina normativa) não enfrenta quaisquer dificuldades ao lidar com fenômenos da ordem do dia tais quais „,soft law“, „governo de múltiplos níveis“ ou „pluralismo jurídico“. A distinção entre normativo e empírico é a chave interpretativa, aqui, de tal forma que a investigação desta última esfera pertence ao domínio das ciências sociais e não da teoria do direito.
\end{abstract}

PALAVRAS-CHAVE: Identidade entre Estado e direito. Hans Kelsen. Teoria pura do direito. Teoria normativa. Pluralismo jurídico.

SUMÁRIO: 1 Transformação do Estado - de que Estado? 1.1 Um Estado, duas dimensões, três elementos? 1.2 Diferenciação dos conceitos de Estado. 1.3 Conceito teórico-jurídico de Estado e transformação do Estado. 2 Transformações do conteúdo do direito. 2.1 Autorregulação. 2.2 »Soft law«. 3 Transformação da estrutura do direito: Substituição do Estado. 3.1 »Sistemas de múltiplos níveis« e »pluralismo jurídico《 como (aparente) desafio a um teoria do direito centrada no Estado. 3.1.1 »Sistemas de múltiplos níveis«. 3.1.2 »Pluralismo jurídico«. 3.2 Substituição, não transformação do Estado. 3.2.1 A antiquada teoria do direito centrada no Estado como quimera. 3.2.2 A necessária unidade da perspectiva jurídica da ciência normativa. 3.2.2.1 Derrogação apenas internamente a uma ordem jurídica. 3.2.2.2 Construção do direito internacional público e do direito europeu. 3.2.3 O caráter arbitrário da escolha do ponto de partida da abordagem jurídica. Conclusão perspectivas científico-normativas e científico-sociais sobre a "transformação do Estado". Referências Bibliográficas.

\footnotetext{
* Publicação original: REIMER, Philipp. »L'État, c'est le droit!« - Zur Aktualität der Staatslehre Hans Kelsens im Angesicht sich wandelnder Staatsgewalt. In: HESCHL, Lisa et seq (Eds.). L'État, c'est quoi? Staatsgewalt im Wandel. 54. Assistententagung Öffentliches Recht. Graz: Helbing \& Lichtenhahn, 2014, p. 37-57. Traduzido por Rodrigo Garcia Cadore, doutorando em Teoria do Direito e Direito Público pela Universidade de Freiburg (Albert-Ludwigs-Universität Freiburg), Alemanha, com autorização do autor.

** Livre-docente em Direito Público e Teoria do Direito pela Universidade de Freiburg (Albert-LudwigsUniversität Freiburg), Alemanha. Professor Privatdozent na Faculdade de Direito da Universidade de Mainz (Johannes Gutenberg Universität Mainz), Alemanha.
} 


\section{Wh

\section{TRANSFORMAÇÃO DO ESTADO - DE QUE ESTADO?}

\subsection{Um Estado, duas dimensões, três elementos?}

A questão acerca do que seja o Estado tem ocupado desde muito tempo não apenas os juristas. Hoje tem-se por fundamentalmente claro que esta questão não pode ser colocada desta maneira, na medida em que a busca por uma "essência" de Estado no firmamento das ideias está, reconhecidamente, fadada ao fracasso. ${ }^{1}$ Somente pode se tratar, aqui, de uma construção conceitual que seja adequada aos respectivos interesses cognitivos em jogo. Sendo assim, a própria questão que serve de ponto de partida a este ciclo de conferências - „»L'État, c'est quoi?« - convida a uma retrospectiva reflexiva desde a perspectiva da teoria da ciência.

A antiga "teoria geral do Estado", como aquela de Georg Jellinek, ${ }^{2}$ nesse sentido, aparece ainda amarrada a um pensamento essencialista. Esta teoria concebe o "Estado" como um ente unitário que poderia se manifestar tanto como uma construção jurídica quanto como uma estrutura fático-socialmente experienciável. ${ }^{3}$ Este Estado pertenceria simultaneamente à esfera do dever ser jurídico e à esfera do ser fático e deveria ser investigado a partir destas “duas dimensões". ${ }^{4}$ Quando se está ou não perante um Estado é algo que haveria de ser determinado por meio da "teoria dos três elementos": um Estado seria, assim, uma organização de poder em exercício, que domina um grupo de seres humanos e um determinado território. ${ }^{5}$

\footnotetext{
${ }^{1}$ Veja-se, sobre a posição de Kelsen, DREIER, Horst. Hans Kelsens Wissenschaftsprogramm. In: SCHULZEFIELITZ, Helmuth (org.). Staatsrechtslehre als Wissenschaft, 2007, p. 81 (p. 96).

2 Sobre a "reabilitação" desta teoria, vide VOSSKUHLE, Andreas. Die Renaissance der »Allgemeinen Staatslehre« im Zeitalter der Europäisierung und Internationalisierung. JuS, v. 44, 2004, p. 2; sobre sua peculiaridade como excepcionalismo [Sonderweg] alemão: LEPSIUS, Oliver. Die Zwei-Seiten-Lehre des Staates. In: ANTER, Andreas (org.). Die normative Kraft des Faktischen, 2004, p. 63 (p. 84 e ss.).

3 JELLINEK, Georg. Allgemeine Staatslehre. 3. ed., 1914, p. 11, 50, 174-183; ainda HOLUBEK, Reinhard. Allgemeine Staatslehre als empirische Wissenschaft, 1961, p. 61-68; ALBERT, Hans-Peter. Der Staat als "Handlungssubjekt", 1988, p. 80-89; KOCH, Hans-Joachim. Die staatsrechtliche Methode im Streit um die Zwei-Seiten-Theorie des Staates (Jellinek, Kelsen, Heller). In: PAULSON, Stanley L.; SCHULTE, Martin (orgs.). Georg Jellinek, 2000, p. 371; LEPSIUS, Oliver. Georg Jellineks Methodenlehre. In: PAULSON, Stanley L.; SCHULTE, Martin (orgs.). op. cit., p. 309 (p. 329-331); LEPSIUS, Oliver. op. cit., p. 63 (p. 84 e ss.).

${ }^{4}$ Sobre os possíveis backgrounds científico-estratégicos desta abordagem, veja-se. KERSTEN, J. Georg Jellinek und die klassische Staatslehre, 2000, p. 149 e ss; para uma crítica epistemológica KELSEN, H. Der soziologische und der juristische Staatsbegriff, 1922, p. 114-120, e, ainda OOYEN, R. Ch. van. Der Staat der Moderne, 2003, p. 28-39.

${ }^{5}$ JELLINEK, G. op. cit., p. 394-434. Sobre o desenvolvimento e recepção [da teoria dos três elementos], veja-se KETTLER, Dietmar. Die Drei-Elemente-Lehre. Ein Beitrag zu Jellineks Staatsbegriff, seiner Fortführung und Kritik, 1995.
} 


\subsection{Diferenciação dos conceitos de Estado}

A construção conceitual da "teoria das duas dimensões" é, contudo, excessivamente indiferenciada - eis uma das principais constatações da Teoria Pura do Direito inaugurada por Hans Kelsen. ${ }^{6}$ O caráter de Janus do "Estado" se manifesta apenas porque dois diferentes objetos podem ser referidos com a mesma palavra: "Estado" pode ser, por um lado, um fenômeno ou uma ordem de coisas fático-social, como uma organização que persegue certos interesses na realidade empírica; com o que se tem em mente um conceito de Estado das ciências sociais (sociológico). Por outro lado, "Estado" designa a estrutura do direito; escolhese, nesse caso, um conceito de Estado das ciências normativas. ${ }^{7}$ Esta cisão de um "Estado" portador de duas faces em dois diferentes "Estados" é uma condição de possibilidade do conhecimento - o que vale para as "duas dimensões do Estado". Um dos objetos pertence à "realidade causal", o outro, à "idealidade normativa"; 8 um conceito é um "conceito natural" [empírico], o outro, um "conceito jurídico". 9

Se deseja-se compreender o Estado sociologicamente, então apenas fatos do ser constituem objeto de interesse cognitivo. ${ }^{10}$ Aqui seria possível um conceito estatal desde a perspectiva das ciências organizacionais ou da teoria dos sistemas, que foca sobre um sistema parcial da sociedade constituído por meio de comunicações específicas. ${ }^{11}$ Em todo caso, tratar-se-ia de "aglomerados de poder simplesmente justapostos de modo fático". ${ }^{12}$

\footnotetext{
${ }^{6}$ Veja-se, por exemplo: KELSEN, Hans. Hauptprobleme der Staatsrechtslehre entwickelt aus der Lehre vom Rechtssatze, 1911, p. 405 e ss. Vide também JESTAEDT, Matthias (org.). Hans Kelsens Werke, v. 2, p. 21 (p. 541-543); KELSEN, Hans. Die soziologische und die juristische Staatsidee (1914). In: JESTAEDT, Matthias (org.). Hans Kelsens Werke, v. 3, p. 201; KELSEN, Hans. Der soziologische und der juristische Staatsbegriff, 1922, p. 105-120; VERDROSS, Alfred. Grundlagen und Grundlegungen des Völkerrechts. Niemeyers Zeitschrift für internationales Recht, v. 29, 1921, p. 65 (p. 84).

7 Sobre a distinção entre abordagens científico-causais e científico-normativas KELSEN, Hans. Reine Rechtslehre, 2. ed., 1960, p. 78 e ss. A distinção aparece também em JELLINEK, G. op. cit., p. 19-21; contudo, ali o Estado é compreendido como um objeto unitário, que deve ser investigado em duas dimensões mediante uma "diversificação do método" (p. 11).

${ }^{8}$ KELSEN, Hans. Der soziologische und der juristische Staatsbegriff, 1922, p. 2.

${ }^{9}$ KELSEN, Hans. Der soziologische und der juristische Staatsbegriff, 1922, p. 117; veja-se também KELSEN, H. Staatsidee (nota de rodapé 6, acima), p. 210.

${ }^{10}$ Apenas em sentido metafórico designa Kelsen esta como a "por assim dizer metade sociológica" do Estado: KELSEN, H.. Staatsform als Rechtsform. Zeitschrift für öffentliches Recht, v. 5, 1926, p. 73 (p. 74),

${ }^{11}$ Veja-se LUHMANN, N. Die Politik der Gesellschaft, 2000, p. 195 e ss., p. 243-253 e passim; LUHMANN, N. Das Recht der Gesellschaft, 1993, p. 582.

${ }^{12}$ DREIER, H. op. cit., p. 95.
} 


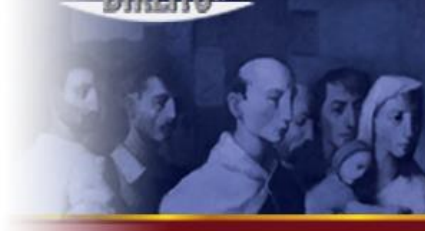

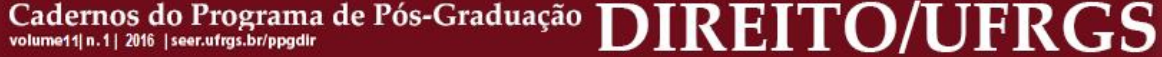

Contudo, mesmo internamente à perspectiva das ciências normativas e da perspectiva jurídica em sentido estrito, "Estado" e "Estado" não possuem o mesmo significado. Antes pelo contrário, aqui deixam-se novamente distinguir (ao menos) dois conceitos de Estado: ${ }^{13}$

»Estado ${ }_{1} \ll$ é a personificação de uma - relativamente centralizada ${ }^{14}$ ordem jurídica total. ${ }^{15}$ Este é o conceito teórico-jurídico de Estado da Teoria Pura do Direito. A este Estado pertencem todas as normas de uma ordem jurídica: desde a constituição até os derradeiros negócios jurídicos, passando pelas decisões judiciais e atos administrativos. ${ }^{16}$

»Estado $2 \ll$ é, por sua vez, a personificação de uma parcela da ordem jurídica, ${ }^{17}$ que é qualificada de determinada maneira - uma »pessoa estatal«, submetida à ordem jurídica. ${ }^{18}$ Do mesmo modo como uma associação ou uma sociedade podem ser compreendidas juridicamente como personificação de seus estatutos, ${ }^{19}$ assim também este »Estado« é uma reunião intelectual das normas que lhe imputam obrigações e direitos. ${ }^{20}$ Este conceito de Estado corresponde à prática linguística da dogmática jurídica. ${ }^{21}$ Para cada norma positivada pode, em conformidade com este entendimento, ser necessário um conceito próprio [de Estado], cujos significado e alcance dependem, em cada caso, da concreta configuração do direito positivo. Pense-se, exemplificativamente, no conceito de Estado do direito

\footnotetext{
${ }^{13}$ Veja-se, por exemplo, KELSEN, Hans. op. cit. (nota de rodapé 7, acima), p. 270; SANDER, Fritz. Zeitschrift für öffentliches Recht, v. 1, 1919/1920, p. 132 (p. 153 nota de rodapé 2).

${ }^{14}$ KELSEN, Hans. (nota de rodapé 7, acima), p. 289 e ss..

15 Veja-se KELSEN, Hans. Über Staatsunrecht. Grünhuts Zeitschrift, v. 40 (1914), p. 1 (p. 9 e ss); igual JESTAEDT, Matthias (org.). Hans Kelsens Werke, v. 3, p. 439 (p. 447); KELSEN, Hans. Les rapports de système entre le droit interne et le droit international public. Recueil des cours de l'Académie de droit international de La Haye, v. 14, 1926, p. 227 (p. 243); Idem. Reine Rechtslehre. 1. ed., 1934, p. 117-121; Idem. Reine Rechtslehre. 2. ed., (nota de rodapé 7, acima), p. 289-293; MERKL, Adolf Julius. Allgemeines Verwaltungsrecht, 1927, p. 291 e ss. Sobre a identificação entre Estado e Direito em Kelsen veja-se, por exemplo, DREIER, H. op. cit. (nota de rodapé 1, acima), p. 95-98.

${ }^{16}$ Sobre o caráter de normas jurídicas destas regulações destinadas a casos singulares, tal qual assumido pela Teoria Pura do Direito, veja-se KELSEN, H. Reine Rechtslehre. 1. ed., (nota de rodapé 15, acima), p. 79-82; Idem. Reine Rechtslehre. 2. ed (nota de rodapé 7, acima), p. 242, 261 e ss.

${ }_{17}$ MERKL, A. J. op. cit. (nota de rodapé 15, acima), p. 293; KELSEN, H. Reine Rechtslehre. 1. ed. (nota de rodapé 15, acima), p. 121-124; Idem. Reine Rechtslehre. 2. ed (nota de rodapé 7, acima), p. 296.

${ }^{18}$ Veja-se, por exemplo, KELSEN, Hans. Staatsidee (nota de rodapé 6, acima), p. 225-227; Idem, Staatsunrecht (nota de rodapé 15, acima), p. 7; igual JESTAEDT, Matthias (org.). Hans Kelsens Werke, v. 3, p. 445. A não tão simples individualização do Estado 2 é tentada por MERKL, A. J. op. cit. (nota de rodapé 15, acima), p. 295, pela via do financiamento; veja-se ainda KELSEN, Hans. op. cit. (nota de rodapé 7, acima), p. 299-301.

19 KELSEN, Hans. Das Problem der Souveränität und die Theorie des Völkerrechts, 1920, p. 20; igual JESTAEDT, Matthias (org.). Hans Kelsens Werke, v. 4, p. 235 (p. 291); KELSEN, Hans. Staat und Völkerrecht. Zeitschrift für öffentliches Recht. v. 4, 1925, p. 207 (p. 220).

${ }^{20}$ Veja-se KELSEN, H. op. cit. (nota de rodapé 7, acima), p. 293.

${ }^{21}$ Com MERKL, Adolf. op. cit. (nota de rodapé 15, acima), p. 304 e ss., pode-se distinguir do »Estado 2 «ainda um »Estado «, que designaria o Estado enquanto conteúdo do direito positivo em sua contraposição a corporações dotadas de autonomia administrativa. Assim fica claro: pode haver inúmeros conceitos de Estado voltados para o conteúdo do direito positivo.
} 


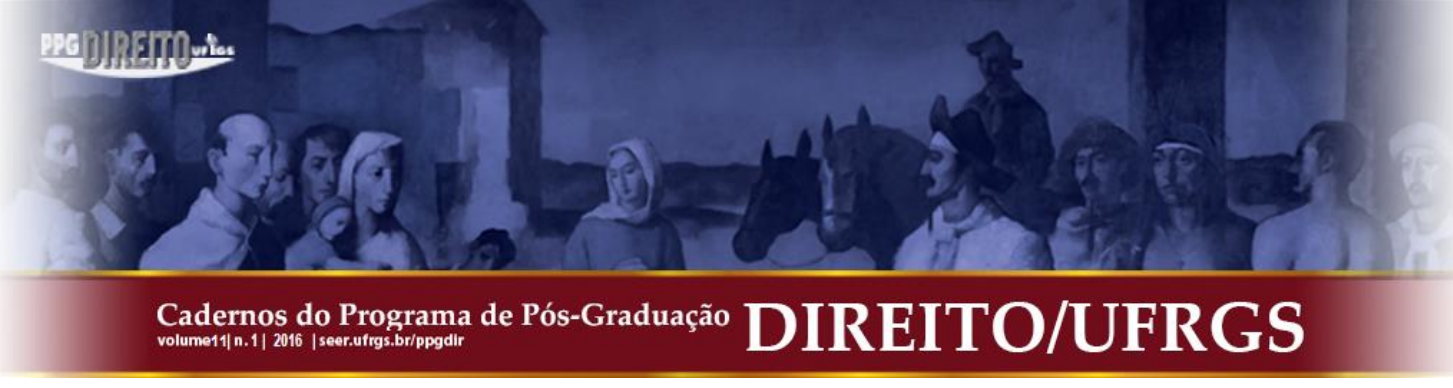

constitucional ou do direito internacional público, como no Art. $34 \S 1^{\circ}$ do Estatuto do Tribunal Internacional de Justiça.

Diante do pano de fundo destas possibilidades de diferenciação, é de se perguntar qual o ponto da insistência de Kelsen no »Estado1« - na insistência de que o »Estado« deve ser compreendido como algo que é idêntico à »ordem jurídica«? A crítica de Kelsen aos conceitos sociológicos de Estado não é de modo algum uma crítica elementar - ele não os considera como carta fora do baralho; ${ }^{22}$ contudo, as definições que procuravam captar o Estado como essência, oferecidas ao seu tempo e que ainda hoje parcialmente resplandecem, ${ }^{23}$ revelam-se ao seu ver como conceitos jurídicos disfarçados e não como conceitos empíricos. ${ }^{24}$ Assim, porém, a relação entre Estado e direito torna-se um »pseudoproblema «, ${ }^{25}$ o que conduz Kelsen a sua teoria jurídica pura do Estado - à »Teoria do Estado sem Estado«, como ele mesmo paradoxalmente formulou. ${ }^{26}$

\subsection{Conceito teórico-jurídico de Estado e transformação do Estado}

Nas páginas seguintes será empreendida uma aproximação teórico-jurídica (a partir da teoria do direito) ao problema da "transformação do Estado". Para tanto, pode-se optar aqui pelo conceito teórico-jurídico de Estado (»Estado1«) e, a partir desta perspectiva, pode-se responder à questão condutora deste ciclo de conferências da seguinte maneira: »L'État, c'est le droit!«

Com este conceito de Estado torna-se perceptível a necessidade de diferenciações no âmago de distintos fenômenos de "transformação do Estado". ${ }^{27}$ Afinal, uma transformação do

\footnotetext{
${ }^{22} \mathrm{O}$ que se pode perceber em KELSEN, H. op. cit. (nota de rodapé 4, acima), p. 253; para outra direção apontam manifestações como as de Kelsen em KELSEN, Hans. Staatsidee (nota de rodapé 6, acima), p. 221.

${ }^{23}$ Do mesmo modo LUHMANN, Niklas. Soziale Systeme, 1984, pp. 626 e ss.. Nota de rodapé 55, com referências que poderiam ser multiplicadas.

${ }^{24}$ Vejam-se as análises no típico método de diálogo em KELSEN, H. op. cit. (nota de rodapé 4, acima), especialmente p. 46-74, pp. 106-120; sobre Jellinek, ainda LEPSIUS, O. op. cit. (nota de rodapé 2, acima), p. 71 e ss., p. 75 e ss..

${ }^{25}$ KELSEN, H. Souveränität (nota de rodapé 19, acima), p. 18 e ss., p.169; igual JESTAEDT, Matthias (org.). Hans Kelsens Werke, v. 4, p. 288 e ss., p. 430; Idem. op. cit. (nota de rodapé 4, acima), p. 133 e passim; Idem. Gott und Staat. Logos, v. 11, 1922/1923, p. 262 (p. 274).

${ }^{26}$ Veja-se. KELSEN, H. Gott und Staat (nota de rodapé 25, acima), p. 283.

${ }^{27}$ Sobre transformação "interna" (»economicização, privatização, desregulação«) e transformação »externa« (»europeização, internalização«) como desafios à teoria do Estado, veja-se SCHULZE-FIELITZ, Helmuth. Staatsrechtslehre als Wissenschaft. In: Idem. op. cit. (nota de rodapé 1, acima), p. 11 (p. 39-43, citações: p. 39 e, mais extamente, p. 40); na ciência política o papo também é sobre transformação "horizontal" e "vertical", vejase FRERICHS, Sabine. Judicial Governance in der europäischen Rechtsgemeinschaft, 2008, p. 42 e ss.
} 


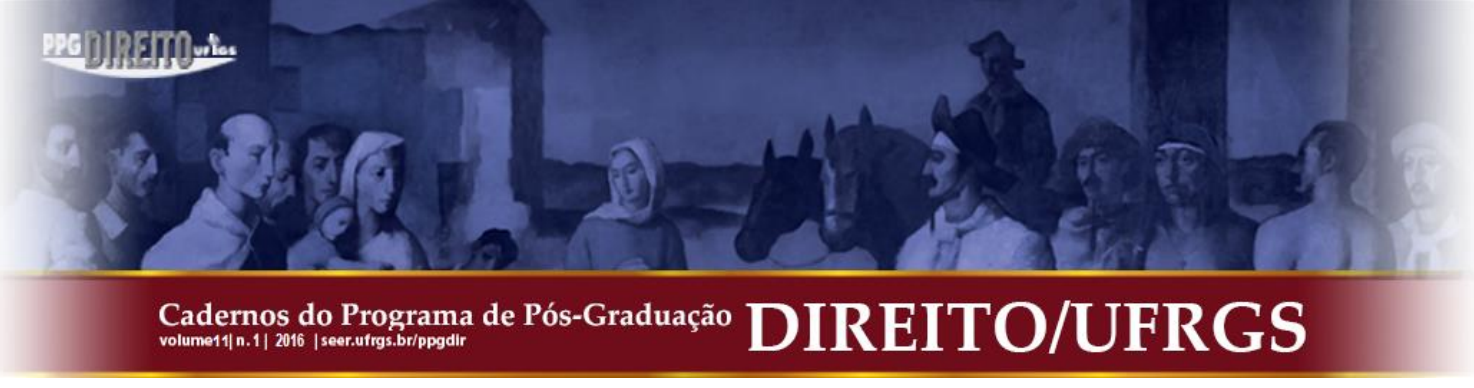

que o sentido deste ato deve adquirir validade jurídica. A "autorregulação" não respresenta, aqui, qualquer exceção.

Uma vez que todas normas de atribuição de poder revelam fudamentalmente a mesma estrutura, não se pode distinguir, em um sentido elementar, entre atribuição de poder ao Estado para a positivação do direito e atribuição de poder para a positivação do direito aos particulares. Na perspectiva do conceito teórico-jurídico de Estado deve-se antes imputar toda criação do direito ao Estado. Órgãos estatais e particulares, são, neste sentido, da mesma forma, centros de imputação - »órgãos jurídicos «. ${ }^{29}$ A distinção entre órgãos estatais e particulares não é jurídico-estrutural, mas sim de tipo contingente, referindo-se aos conteúdos jurídicos.

\section{$2.2 »$ Soft law»}

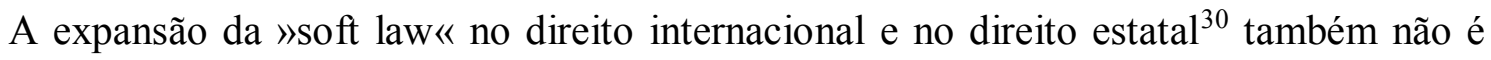
visualizável a partir de uma perspectiva científico-normativa, porque (e enquanto) ela não produz qualquer efeito jurídico. ${ }^{31} »$ Soft law « seriam textos proclamados ou pactuados, por meios dos quais os seus autores explicitamente não pretendem estabelecer normas jurídicas. ${ }^{32}$ Tratam-se de declarações de propósitos ou de manifestações de desejos, mas também de obras de regulação cabalmente lapidadas. ${ }^{33}$

A "criação" de »soft law« se desdobra externamente à estrutura de criação do direito [Rechtserzeugungszusammenhang] de uma ordem jurídica. »Soft law« encontra-se, assim, não no interior, ${ }^{34}$ mas sim fora da hierarquia normativa. O mesmo vale também para as

\footnotetext{
${ }^{29}$ Veja-se. KELSEN, H. op. cit. (nota de rodapé 7, acima), p. 157; MERKL, A. J. op. cit. (nota de rodapé 15, acima), p. 291 e ss..

${ }^{30}$ Sobre a emergência deste fenômeno em ambas as ordens, já JABLONER, Clemens; OKRESEK, Wolf, Theoretische und praktische Anmerkungen zu Phänomenen des »soft law«. Österreichische Zeitschrift für öffentliches Recht. v. 34, 1983, p. 217 (p. 218); HEUSEL, Wolfgang. »Weiches « Völkerrecht, 1989.

${ }^{31}$ Para o tratamento da "soft law" em diferentes perspectivas teóricas veja-se GOLDMANN, Matthias. We Need to Cut Off the Head of the King. Leiden Journal of International Law. v. 25, 2012, p. 335 (p. 339-366).

${ }^{32}$ Sobre a história do conceito veja-se ARNDT, Dominik E. Sinn und Unsinn von Soft Law, 2011, p. 36-41; para diferentes propostas de definição KLABBERS, Jan. The Redundancy of Soft Law. Nordic Journal of International Law. v. 65, 1996, p. 167 (p. 168) com outras referências.

${ }^{3}$ Para a práxis estatal do "direito maleável" veja-se o detalhado inventário em HEUSEL, Wolfgang. op. cit. (nota de rodapé 30, acima), p. 47-273.

${ }^{34}$ Nesse sentido, contudo, de modo evidente SENDEN, Linda. Soft Law in European Community Law, 2004, p. 59.
} 


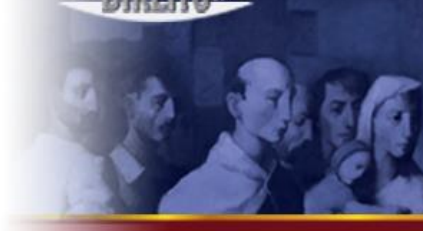

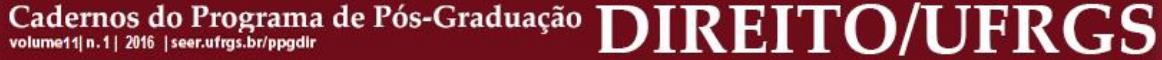

situações em que o direito positivo estabelece expressamente diretrizes para a $» \operatorname{soft}$ law « ${ }^{35}$ (pois também podem existir condições jurídicas para ações cujo conteúdo não se reveste de qualquer caráter juridicamente vinculante, como no âmbito dos atos administrativos reais [Verwaltungsrealakte]) ou enuncia atribuições de $\operatorname{poder}^{36}$ (não se tratam, aqui, na falta de caráter jurídico vinculante, de atribuições de poder para a criação de direito). Do mesmo modo, apenas um costume efetivamente observador da "soft law" torna-se direito (internacional público) costumeiro, não a própria "soft law". Do ponto de vista científiconormativo, nestes casos é no máximo observável (se não se quiser investigar o próprio documento de "soft law" por meio de método jurídico como ordem jurídica autônoma) que se desistiu da utilização de atribuições de poder para a criação do direito, em função de quais razões (políticas) isso acontece é algo que se situa fora das competências disciplinares da teoria e da dogmática jurídicas, projetando-se para o campo das ciências sociais. Que se fale de uma "soft law" é algo que, em dado sentido, obscurece a compreensão desta ordem de coisas, pois esta construção conceitual insinua que se trataria aqui de um fenômeno intrínseco à ordem jurídica. ${ }^{37}$

Substancialmente, deve-se registrar que: uma "norma jurídica maleável" é uma contradição em termos, pois, ou se tem uma norma jurídica, e então equipara-se esta norma a todas as demais normas pertencentes à ordem jurídica como parte integrante dela, ou não se trata de norma jurídica alguma, e por isso mesmo não se tem uma "norma jurídica maleável". ${ }^{38}$ Tertium non datur. ${ }^{39}$ Mesmo a referência à relevância política, que, sem dúvidas, deve ser conferida à "soft law", ${ }^{40}$ antes serve de apoio a esta afirmação, invés de enfraquecê-

\footnotetext{
${ }^{35}$ Como se costuma assumir especialmente com relação à "soft law" dos órgãos da União Europeia, veja-se SCHWARZE, Jürgen. Soft Law im Recht der Europäischen Union. Europarecht (EuR). v. 46, 2011, p. 3 (p. 916).

${ }^{36}$ Como por exemplo no Art. $288 \S 5^{\circ}$ do AEUV (Tratado sobre o funcionamento da União Europeia).

${ }^{37}$ Isso permanece de modo não unívoco em EHRICKE, Ulrich. »Soft law« - Aspekte einer neuen Rechtsquelle. Neue Juristische Wochenschrift (NJW). v. 31, p. 1989, p. 1906 (p. 1907).

${ }^{38}$ Como em KLABBERS, Jan. op. cit. (nota de rodapé 32, acima); também em KNAUFF, Matthias. Der Regelungsverbund, 2010, p. 528 e ss.

39 Veja-se WEIL, Prosper., Towards Relative Normativity in International Law? American Journal of International Law (AJIL). v. 77, p. 1983, p. 413 (p. 414). - Diversamente ARNDT, D. E. op. cit. (nota de rodapé 32, acima), p. 124-128 e passim, que tem em mente »uma renúncia à dicotomia das fontes do direito« (Idem, p. 124) e assume, no lugar dela, uma "irrigação osmótica" entre »hard law« e »soft law« (Idem, p. 126; instrutivas também as construções em Idem, p. 126, 128); levantando dúvidas KNAUFF, M. op. cit. (nota de rodapé 38, acima), p. 18, 224-227.

${ }^{40}$ Do mesmo modo em HEUSEL, Wolfgang. op. cit. (nota de rodapé 30, acima), p. 289; criticamente, desde a perspectiva dos práticos SOLTĖSZ, Ulrich. Europäisches "Soft Law《 - Ein Wesen ohne Kuschelfaktor. Europäische Zeitschrift für Wirtschaftsrecht (EuZW). v. 24, 2013, p. 881.
} 


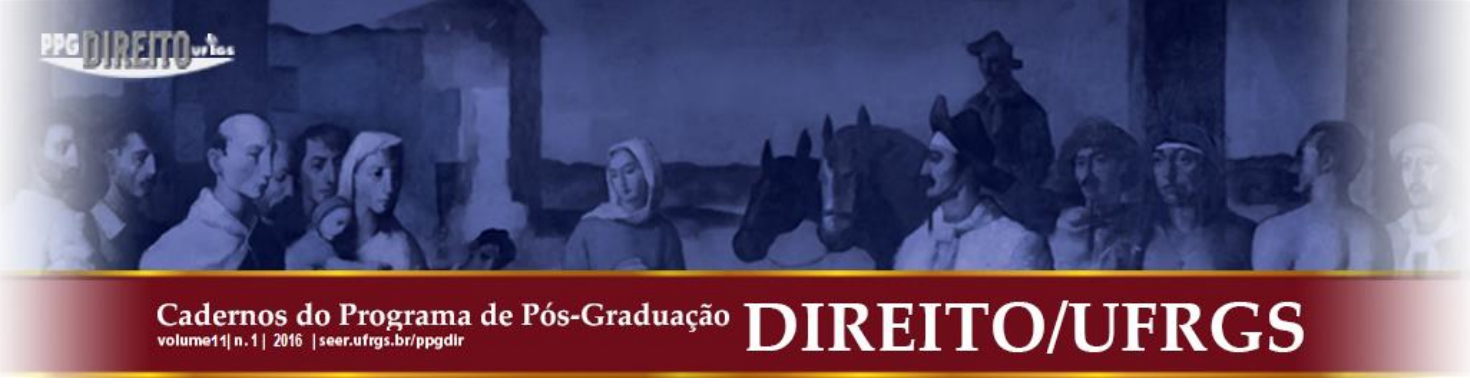

la: ${ }^{41}$ seus impactos [da soft law] são impactos políticos decorrentes do fato de que determinados homens manifestaram determinadas declarações e não consequências jurídicas, que se conectariam à realização de determinado suporte fático [Tatbestand].

É claro: enquanto ação humana a criação de »soft law« não possui qualquer qualidade diversa da ação por meio da qual uma norma de »hard law« é positivada. Ambas são, em si mesmas, apenas um "fato prejurídico", pois mesmo a ação humana que, conforme o seu sentido, estabelece um comando jurídico, não pode, por si só, produzir vincualção jurídica. ${ }^{42}$ Uma norma que emerge como sentido de um ato humano de vontade obtém caráter vinculante quando e somente enquanto estão à disposição normas de atribuição de poder com base nas quais ela pode ser interpretada como norma jurídica ${ }^{43}$ e por meio das quais é possível reconduzi-la à cadeia de produção normativa de uma específica ordem jurídica. Declarações de propósitos, sugestões de regulação ou manifestações de desejos não produzem, diante deste pano de fundo, sem mais, quaisquer consequências jurídicas, não se manifestando, no direito válido, de modo geral, como suportes fáticos aos quais normas de atribuição de poder conectam consequências jurídicas. ${ }^{44}$ Diante desta constelação, não se precisa, desde o ponto de vista da teoria do direito, do conceito de "soft law".

Para uma observação empírico-científica inexistem quaisquer motivos, por sua vez, para não levar em consideração declarações de propósitos, sugestões de regulação, manifestações de desejo e similares atos de positivação da "soft law". ${ }^{45}$ Aqui seria, pelo contrário, um equívoco providenciar prontamente um tratamento especial à "hard law" enquanto tal; ${ }^{46}$ isso porque normas jurídicas não produzem efeitos na realidade a partir de si mesmas, mas sim

\footnotetext{
${ }^{41}$ Veja-se também KLABBERS, Jan. op. cit. (nota de rodapé 32, acima), p. 180, nota de rodapé 65.

${ }^{42}$ Nesse sentido, contudo, de modo evidente HEUSEL, W. op. cit. (nota de rodapé 30, acima), p. 275. Veja-se ainda KELSEN, H. Was ist ein Rechtsakt?. Österreichische Zeitschrift für öffentliches Recht. v. 4 (1952), p. 263 (p. 273 e ss.).

${ }^{43}$ Vgl. KELSEN, Hans. Reine Rechtslehre. 1. ed. (nota de rodapé 15, acima), p. 4 e ss; Idem. Reine Rechtslehre. 2. ed. (nota de rodapé 7, acima), p. 3 e ss.

${ }^{44}$ Assim também em KNAUFF, M. op. cit. (nota de rodapé 38, acima), p. 397; sobre isso, veja-se ARNDT, D. E. op. cit. (nota de rodapé 32, acima), p. 44-50.

${ }^{45}$ Algo semelhante vale para a antropologia jurídica, veja-se MOORE, Sally Falk. Law as Process, 1978, 3 f. Exemplos ao redor do mundo atinentes à questão da governance em KIRTON, J. J.; TREBILCOCK, M. J. op . cit. (nota de rodapé 28 , acima).

${ }^{46}$ Nesse sentido, deve-se concordar com GOLDMANN, M. op. cit. (nota de rodapé 31, acima), p. 366-368: enquanto projeto para as ciências empíricas, a "autoridade internacional pública" talvez seja um objeto melhor delimitado do que o "direito".
} 


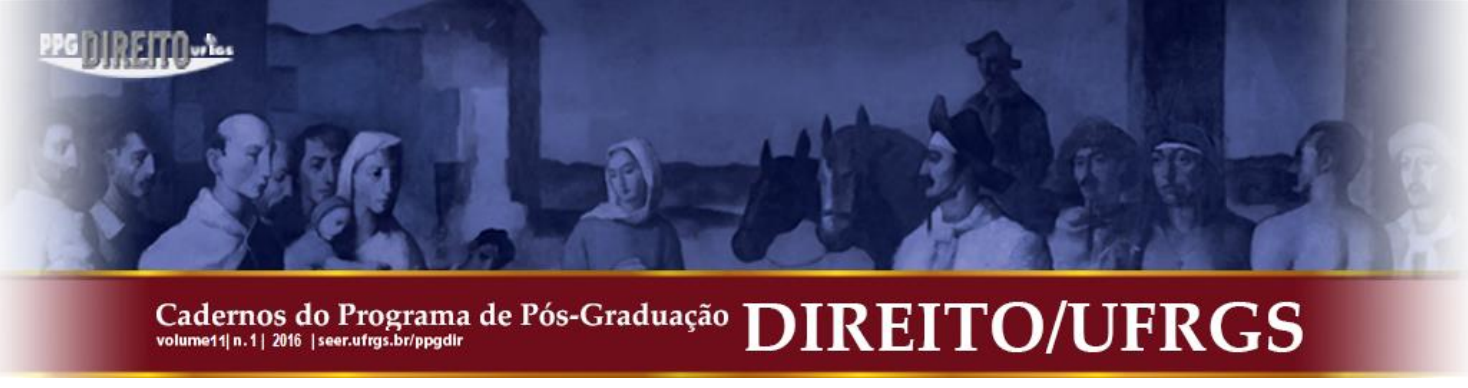

"sistema de múltiplos níveis“ parece já ser suficiente para borrar as fronteiras entre as perspectivas das ciências normativas e das ciências sociais. ${ }^{51}$

Registre-se, contudo, que as abordagens de pesquisa que são catalogadas sob esta rubrica promanam preponderantemente da ciência política, mais exatamente: da pesquisa sobre governance. ${ }^{52}$ Governance é compreendida, aí, como o conjunto de tentativas de regulação de diferentes atores que, na realização de sua tarefa, se amparam no „interesse público" ou no "bem comum". ${ }^{53}$ Legiferação é, assim, uma das diversas formas (efetivamente existentes) que estas tentativas de regulação podem assumir; ${ }^{54}$ neste caso a ciência política descreve um setor da realidade social em que a ciência jurídica reconhece atos positivos de criação de normas. ${ }^{55} \mathrm{Se}$ se deixa de fora a pesquisa de governance para focar sobre o aspecto científico-normativo do tema, tratar-se-ia, então, no caso dos sistemas de múltiplos níveis, do fenômeno de ordens jurídicas de alguma forma entrelaçadas. Este processo tem sido percebido em primeira linha no desenvolvimento da União Europeia (,uma ordem de direito internacional público juridicamente singular“ [»partikularrechtliche Völkerrechtsordnung] ${ }^{56}$ ), mas também nos processos de "constitucionalização" do direito internacional público. ${ }^{57} \mathrm{Em}$ ambos âmbitos parece ter lugar uma superposição [Überlagerung] ou reformulação [Überformung] do direito estatal. ${ }^{58}$ Por meio da expansão das competências supranacionais da União Europeia, que não haveria de constituir um Estado em si mesma, ${ }^{59}$ o poder estatal na

\footnotetext{
${ }^{51}$ Do mesmo modo JESTAEDT, Matthias. Der Europäische Verfassungsverbund. GS W. Blomeyer, 2004, p. 637 (p. 657 e ss.).

${ }_{52}$ Do mesmo modo MAYER, Franz C. Verfassungswandel durch Annäherung? In: HÖNNIGE, Ch.; KNEIP, S.; LORENZ, A. (orgs.). Verfassungswandel im Mehrebenensystem, 2011, p. 272 (p. 294); veja-se, por exemplo, PIATTONI, Simona. The Theory of Multi-level Governance, 2010; ENDERLEIN, H.; WÄLTI, S.; ZÜRN, M. op. cit. (nota de rodapé 47, acima); BRUNNENGRÄBER, Achim; BURCHARDT, Hans-Jürgen; GÖRG, Christoph (orgs.). Mit mehr Ebenen zu mehr Gestaltung?, 2008; de modo tendencialmente cético SECKELMANN, Margrit. Keine Alternative zur Staatlichkeit - Zum Konzept der »Global Governance«. Verwaltungsarchiv. v. 98, 2007, p. 30.

${ }^{53}$ Veja-se ZÜRN, Michael; WÄLTI, Sonja; ENDERLEIN, Henrik. Introduction. In: ENDERLEIN, H.; WÄLTI, S.; ZÜRN, M. op. cit. (nota de rodapé 47, acima), p. 1 (p. 2) com outras referências.

${ }^{54}$ Proposta de definição em HUMRICH, C.; ZANGL, B. op. cit. (nota de rodapé 47, acima), p. 343. Aqui revelase o problema tradicional com sinais trocados: a ciência política se apropria (aparentemente) de categorias imanentemente jurídicas.

${ }_{55}^{5}$ Veja-se KELSEN, H. op. cit. (nota de rodapé 42), p. 273 e ss.

${ }^{56}$ GRILLER, Stefan. Völkerrecht und Landesrecht. In: WALTER, R.; JABLONER, C.; ZELENY, K. (orgs.). Hans Kelsen und das Völkerrecht, 2004, p. 83 (p. 112).

${ }^{57}$ Sobre isso, agora de modo abrangente KLEINLEIN, Thomas. Konstitutionalisierung im Völkerrecht, 2012.

58 GÜNTHER, Klaus. Rechtspluralismus und universaler Code der Legalität. In: GÜNTHER, Klaus; WINGERT, Lutz. Die Öffentlichkeit der Vernunft und die Vernunft der Öffentlichkeit: Festschrift für Habermas, 2001, p. 539 (p. 539).

${ }^{59}$ Para a discussão em torno da classificação da União Europeia, veja-se SCHÖNBERGER, Christoph. Die Europäische Union als Bund. Archiv des öffentlichen Rechts (AöR). v. 129, 2004, p. 81.
} 


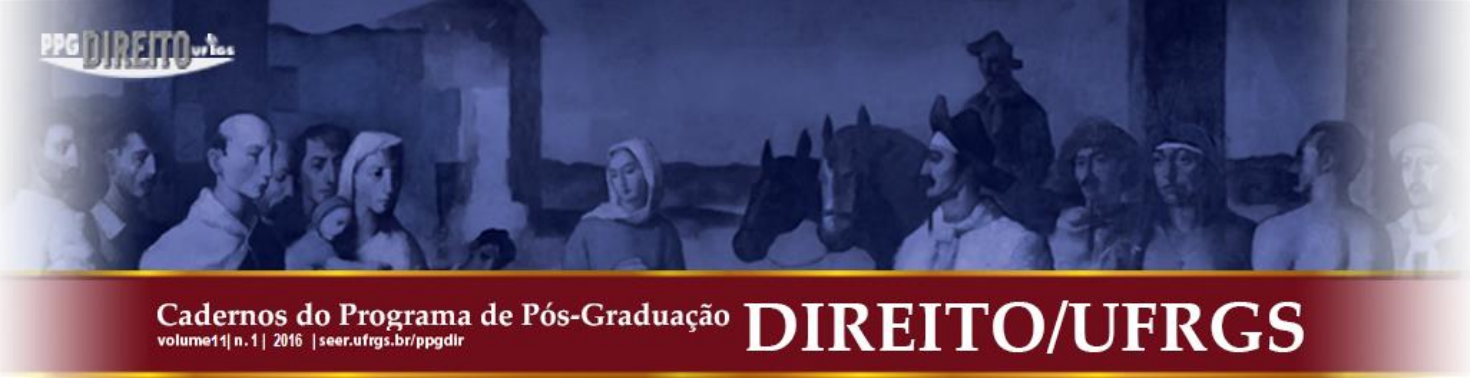

Europa, segundo a concepção corrente, sofreu uma especial relativização - um fenômeno de "transformação" por excelência.

\section{$3.1 .2 »$ Pluralismo jurídico«}

Nos escritos correspondentes, as reflexões sobre um sistema de „múltiplos níveis” costumam ser expandidas em direção a uma "estrutura jurídica policêntrica" [»polyzentrisches Rechtsgefüge ${ }^{60}{ }^{61}$ - mesmo a ideia de uma "rede constitucional" [Verfassungsverbund] aparece fundamentalmente como proposta aqui. ${ }^{62} \mathrm{O}$,estatismo jurídico“ [»Rechtsetatismus« $]^{63}$ e, com ele, a ideia de um fixo "numerus clausus de normas jurídicas" ${ }^{\prime 4}$ são, então, declarados como liquidados. No seu lugar haveria de entrar um pluralismo jurídico no qual vários complexos normativos valem paralelamente, ${ }^{65}$ enquanto "diversos circuitos de influência" [»diverse Einwirkungsströme«] fluem por entre as diversas fontes jurídicas ${ }^{66}$. Este direito se distanciaria cada vez mais do "complexo estatal organizado, burocrático e racionalizado". ${ }^{67}$ A aderência da teoria jurídica ao Estado como centro do direito seria ideologicamente condicionada e, fundamentalmente, acientífica. ${ }^{68}$ Isso porque um "pluralismo jurídico transnacional” estaria se desenvolvendo de modo espontâneo e

\footnotetext{
${ }^{60}$ ARNDT, D. E. op. cit. (nota de rodapé 32, acima), p. 208 - Destaques foram omitidos.

${ }^{61}$ Veja-se BOGDANDY, Armin von. Pluralism, direct effect, and the ultimate say. $I \cdot C O N$. v. 6, 2008, p. 397; BERMAN, Paul Schiff. Global Legal Pluralism. Southern California Law Review. v. 80, 2007, p. 1155.

${ }^{62}$ Uma crítica articulada desde a perspectiva da teoria do direito à noção de uma "rede constitucional" (Verfassungsverbund), segundo a qual "na constituição europeia de múltiplos níveis o direito constitucional da ordem jurídica do(s) estado(s) membro(s) se funde em um sistema jurídico policêntrico com o direito constitucional da ordem jurídica da união europeia, mantendo-se a autonomia das duas massas jurídicas e (...) esta unidade se produz de modo cooperativo, não hierárquico", veja-se JESTAEDT, M. op. cit. (nota de rodapé 51, acima), p. 657-673 (Citação na p. 657 - Destaque no original).

${ }_{63}$ Conceito em LAMPE, Ernst-Joachim. Vorwort. In: Idem (org.). Rechtsgleichheit und Rechtspluralismus, 1995, p. 3 (p. 3).

${ }^{64}$ ARNDT, D. E. op. cit. (nota de rodapé 32, acima), p. 208 com outras referências.

${ }^{65}$ RÖHL, Klaus F.; MACHURA, Stefan. 100 Jahre Rechtssoziologie: Eugen Ehrlichs Rechtspluralismus heute. Juristenzeitung (JZ). v. 68, 2013, p. 1117 (p. 1120).

${ }^{66}$ ARNDT, D. E. op. cit. (nota de rodapé 32, acima), p. 208. - Visão panorâmica sobre as abordagens referentes ao pluralismo jurídico em RÖHL, K. F.; MACHURA, S. op. cit. (nota de rodapé 65, acima); MELISSARIS, Emmanuel. Ubiquitous Law, 2009, p. 43. Com TEUBNER, Gunther. Rechtspluralismus in der Spätmoderne. In: SCHMIDT, Eike et seq. (org.). Liber Amicorum J. Esser, 1995, p. 191 (p. 191): »Pluralismo jurídico é o fascínio dos juristas pós-modernos«

${ }^{67}$ GÜNTHER, K. op. cit. (nota de rodapé 58, acima), p. 557 e ss (citação na p. 557).

${ }^{68}$ Veja-se, para referências a este pluralismo jurídico hard RÖHL, K. F. e MACHURA, Stefan. op. cit. (nota de rodapé 65 , acima), p. 1123 e ss.
} 


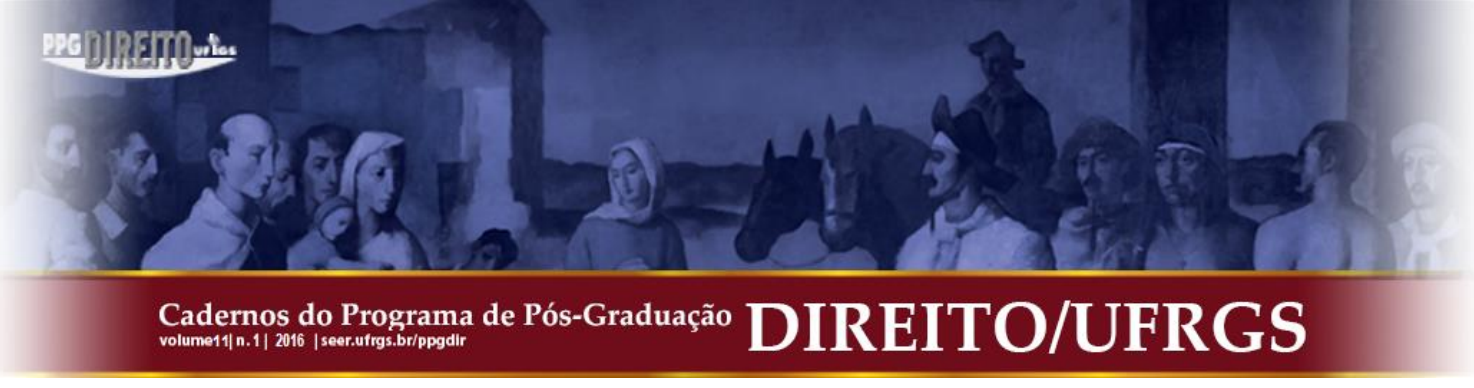

independentemente de Estados. ${ }^{69}$ Aqui poderia ser enquadrada também a emergência de uma ordem jurídica global nas transações econômicas mundiais, que adquiriria validade de modo desvinculado da atividade estatal. ${ }^{70}$

\subsection{Substituição, não transformação do Estado}

\subsubsection{A antiquada teoria do direito centrada no Estado como quimera}

A teoria jurídica centrada no Estado, à qual são endereçadas as censuras de anacronismo $^{71}$ acima noticiadas, é, todavia, uma quimera. Ela não existe nesta forma, uma vez que a teoria do direito pode, basicamente, ocupar-se de quaisquer ordens jurídicas. »O Estado« somente se encontra necessariamente no seu centro se por Estado se entende a personificação de uma ordem jurídica total (»Estado ${ }_{1}$ no sentido do que foi discutido no item 1.2, acima) (e, assim, deixa de ocupar esta posição se este conceito passa a designar somente uma ordem jurídica relativamente centralizada).

Uma ordem jurídica pode reconhecer como atos criadores de normas ações que, simultaneamente, constituem um Estado no sentido fático-social-institucional, desde a perspectiva das ciências sociais ${ }^{72}$ uma tal ordem jurídica constitui, na maioria das vezes, também objeto de perspectiva científico-normativa. ${ }^{73}$ Todavia, qualquer ordem jurídica, ou melhor, qualquer odem normativa é acessível a esta perspectiva (a princípio, inclusive aquelas destituídas de caráter coercitivo).$^{74} \mathrm{O}$ direito canônico, que academicamente costuma ser tratado como uma ordem normativa autônoma, oferece, aqui, um exemplo disso. O reproche

\footnotetext{
${ }^{69}$ TEUBNER, G. Globale Bukowina. Rechtshistorisches Journal. v. 15 (1996), p. 255 (no subtítulo); para "policentricidade da autoria e do controle sobre ele [isto é, o direito] « veja também MELISSARIS, E. op. cit. (nota de rodapé 66, acima), p. 6 e passim.

${ }^{70}$ Veja-se, sobretudo, TEUBNER, G. op. cit. (nota de rodapé 69, acima); de modo crítico com relação a esta construção (da teoria dos sistemas) de pluralismo jurídico LURGER, Brigitta. Der Pluralismus der >lex mercatoriar. Rechtshistorisches Journal. v. 16, 1997, p. 705 (p. 707). Ainda sobre pluralismo transnacional RÖHL, K. F. e MACHURA, S. op. cit. (nota de rodapé 65, acima), pp. 1124-1126.

${ }^{71}$ Veja-se ainda TWINING, William. Globalisation and Legal Theory, 2000, p. 252.

${ }^{72}$ Veja-se KELSEN, Hans. Staatsidee (nota de rodapé 6, acima), p. 210.

${ }^{73}$ Nesse sentido, com base na Teoria Pura do Direito, veja-se MAYER, Hans. Reine Rechtslehre und Gemeinschaftsrecht. In: WALTER, R.; JABLONER, C.; ZELENY, K. op. cit. (nota de rodapé 56, acima), p. 121 (p. 121).

${ }^{74}$ Até mesmo ordens normativas fictícias - veja-se, por exemplo SCHARF, Michael P.; ROBERTS, Lawrence D. The Interstellar Relations of the Federation: International Law and »Star Trek. The Next Generation«. University of Toledo Law Review. v. 25, 1994, p. 577.
} 


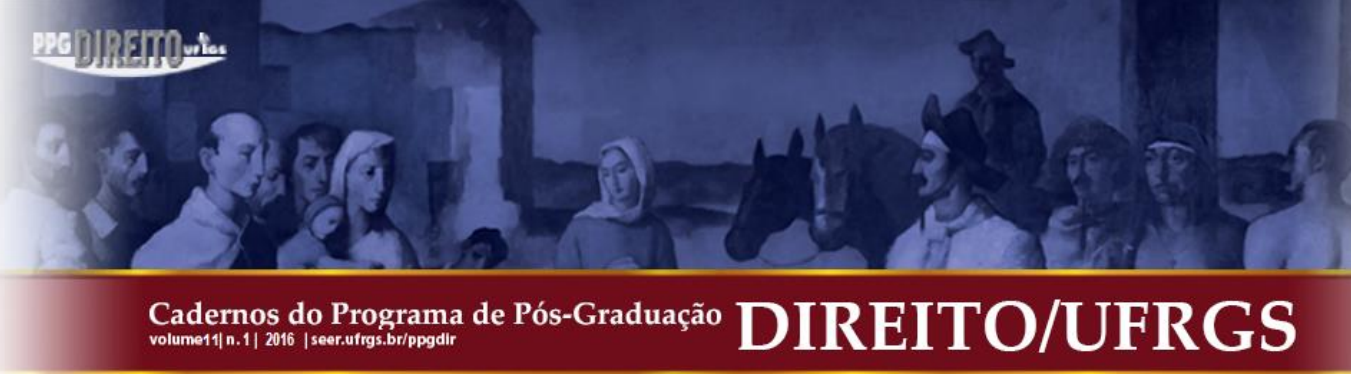

de estadocentrismo [Staatszentriertheit] não atinge, de qualquer modo, a teoria do direito kelseniana, uma vez que aqui estão em jogo distintos conceitos de Estado.

Quando o pluralismo jurídico critica a insistência da teoria do direito na unidade, então ataca-se algo que é inevitável desde a perspectiva científico-normativa: a pertinência de normas jurídicas a uma ordem jurídica em função de uma estrutura de criação do direito [Rechtserzeugungszusammenhang], sem a qual não se pode sequer falar em ordem jurídica. Que esta unidade seja avistada como unidade fictícia desde o ponto de vista das ciências sociais $^{75}$ é algo que não se choca com o que foi dito aqui - esta afirmação se move em um sistema de validação completamente distinto do das ciências normativas.

\subsubsection{A necessária unidade da perspectiva jurídica da ciência normativa}

Engajando-se numa perspectiva científico-normativa e submetendo-se as construções de "sistema de múltiplos níveis" e de "pluralismo jurídico" ao olhar frio da teoria do direito, a charmosa concepção de uma "validade jurídica sem mais", ${ }^{76}$ independente de uma estrutura de criação [do direito], perde rapidamente o seu poder de convencimento. ${ }^{77}$ Por mais que, desde o ponto de vista das ciências sociais, atores possam ser observados nos processos de criação e observância de regras, isso nada diz a respeito da qualificação científico-normativa das regras assim criadas e obedecidas. Para que estas regras possam ser percebidas como normas jurídicas, elas precisam ser pensadas como componentes de uma estrutura de criação do direito [Rechtserzeugungszusammenhang], cujas normas derivam sua validade a partir de outras normas pertencentes à mesma estrutura; ${ }^{78}$ a validade de toda a estrutura enquanto ordem jurídica pode ser apenas assumida como hipótese, já que nem a natureza nem a moral estão em condição de funcionar como fundamentações últimas. ${ }^{79}$

\footnotetext{
${ }^{75}$ Veja-se GÜNTHER, K. op. cit. (nota de rodapé 58, acima), p. 558.

${ }^{76}$ Pressuposta também em WÜRTENBERGER, Thomas. Rechtspluralismus oder Rechtsetatismus? In: LAMPE, E. J. op. cit. (nota de rodapé 63, acima), p. 92 (p. 92).

${ }^{77}$ Como feito aqui JESTAEDT, M. op. cit. (nota de rodapé 51, acima), p. 658.

${ }^{78}$ A derivação da validade no interior de uma estrutura de criação do direito [Rechtserzeugungszusammenhang] nao há de ser concebida de modo simplista-hierárquico; veja-se WIEDERIN, Ewald. Die Stufenbaulehre Adolf Julius Merkls. In: GRILLER, S.; RILL, H. P. (orgs.). Rechtstheorie, 2011, p. 81 (p. 90 e ss) com referências.

${ }^{79}$ Sobre »a validade do sistema e a validade no sistema« veja-se o assim intitulado artigo de JESTAEDT, M. Geltung des Systems und Geltung im System. Juristenzeitung (JZ). v. 68, 2013, p. 1009. Em VERDROSS, Alfred. Die Verfassung der Völkerrechtsgemeinschaft, 1926, p. 22 ss, faz-se da validade hipotética uma validade objetiva, categórica; o autor deixa, com isso, o terreno da Teoria Pura.
} 


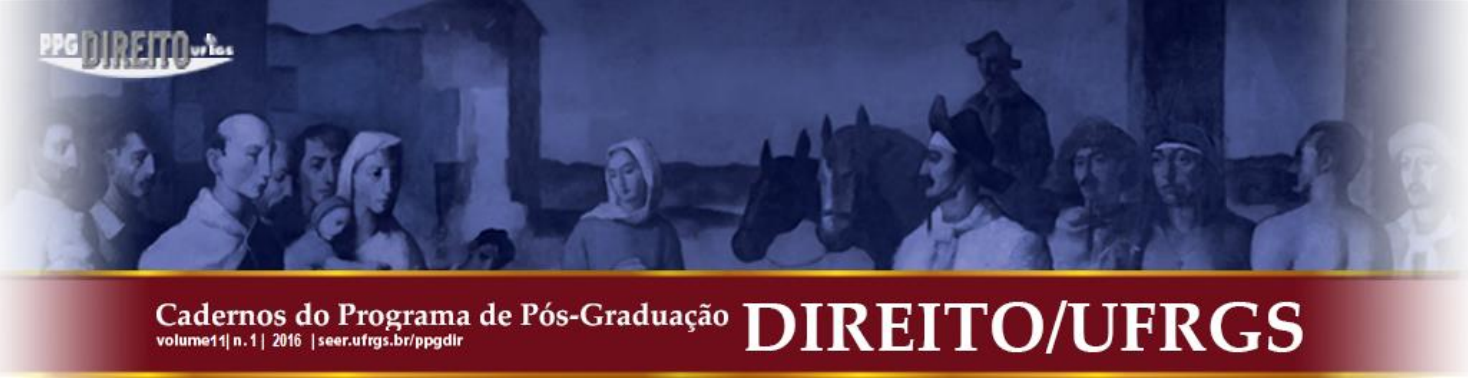

Do ponto de vista da teoria do direito não se pode falar em ordens jurídicas situadas umas ao lado das outras no sentido de um "pluralismo jurídico" ou de um "sistema de múltiplos níveis". Se estas diversas ordens jurídicas devem não apenas ser descritas como faticamente eficazes, isto é, como fatos apreensíveis empírico-cientificamente, ${ }^{80}$ mas sim também como normas jurídicas, então deve ser assumido um ponto de vista comum - a validade de todas estas normas deve poder ser reconduzida a uma mesma hipótese originária. ${ }^{8182}$ Diversas ordens jurídicas entre as quais venham a existir relações ${ }^{83}$ devem ser, assim, concebidas como "ordens parciais" integrantes de uma "ordem total". 84

$\mathrm{Na}$ ausência de um tal ponto de partida comum ${ }^{85}$ não se podem fundamentar interações normativas entre estas ordens (sobre isso, veja-se a discussão em 3.2.2.1, imediatamente abaixo); ${ }^{86}$ as ordens não se reconhecem umas às outras como direito. ${ }^{87}$ Direito europeu e direito internacional público devem, por isso, ser construídos em conexão com as ordens jurídicas dos estados particulares, a fim de que se possa chegar a interações normativas recíprocas (sobre isso 3.2.2.2).

\footnotetext{
${ }^{80}$ Veja-se JESTAEDT, M. op. cit. (nota de rodapé 51, acima), p. 659. Fatos do ser é o que tem, claramente, diante dos olhos BOGDANDY, A. v. op. cit. (nota de rodapé 61, acima), p. 400.

${ }^{81} \mathrm{O}$ conceito aparece (com variações) sobretudo no jovem Kelsen, lá onde, mais tarde, fala-se em "norma fundamental" [»Grundnorm《]; veja-se KELSEN, H. Souveränität (nota de rodapé 19, acima), p. 29 e passim, igual JESTAEDT, Matthias (org.). Hans Kelsens Werke, v. 4, p. 300 e passim.

${ }^{82}$ KELSEN, Hans. Staat (nota de rodapé 19, acima), p. 209, p. 216; VERDROSS, A. op. cit. (nota de rodapé 79, acima), especialmente p. 34-42. Contra a assunção kelseniana da impossibilidade de uma construção dualista, todavia GRILLER, Stefan. op. cit. (nota de rodapé 56, acima), p. 87-89; KAMMERHOFER, Jörg. Kelsen Which Kelsen? A Reapplication of the Pure Theory to International Law. Leiden Journal of International Law. v. 22,2009 , p. 225 (p. 243).

${ }^{83}$ Essa delimitação é necessária, na medida em que a fundamentação epistemológica da unidade de todo direito acolhida pelo próprio Kelsen pouco contribui, aqui; sobre isso KAMMERHOFER, J. op. cit. (nota de rodapé 82, acima), p. 240 e ss. De modo semelhante JESTAEDT, M. op. cit. (nota de rodapé 51, acima), p. 667.

${ }^{84}$ Par conceitual em: KELSEN, Hans. Die Einheit von Völkerrecht und staatlichem Recht. Zeitschrift für ausländisches öffentliches Recht und Völkerrecht (ZaöRV). v. 19, 1958, p. 234 (p. 235); de modo semelhante Idem. op. cit. (nota de rodapé 7, acima), p. 332 e ss..

${ }^{85}$ Este conceito já se encontra em VERDROSS, Alfred. Zur Konstruktion des Völkerrechts. Zeitschrift für Völkerrecht. v. 8, 1914, p. 329 (p. 333).

${ }^{86}$ Veja-se ainda JESTAEDT, M. op. cit, (nota de rodapé 51, acima), p. 667; Idem. Konkurrenz von Rechtsdeutungen statt Koexistenz von Rechtsordnungen. In: BRUNKHORST, H.; VOIGT, R. (orgs.). RechtsStaat, 2008, p. 233 (p. 236 e ss).

${ }^{87}$ Veja-se KELSEN, H. General Theory of Law and State, 1945, p. 374. Não se trata aí de uma assunção harmônica da sistematicidade interna dos ordenamentos; assim, entretanto, as - de modo algum atípicas? incompreensões com relação a Kelsen em TWINING, W. op. cit. (nota de rodapé 71, acima), p. 62.
} 


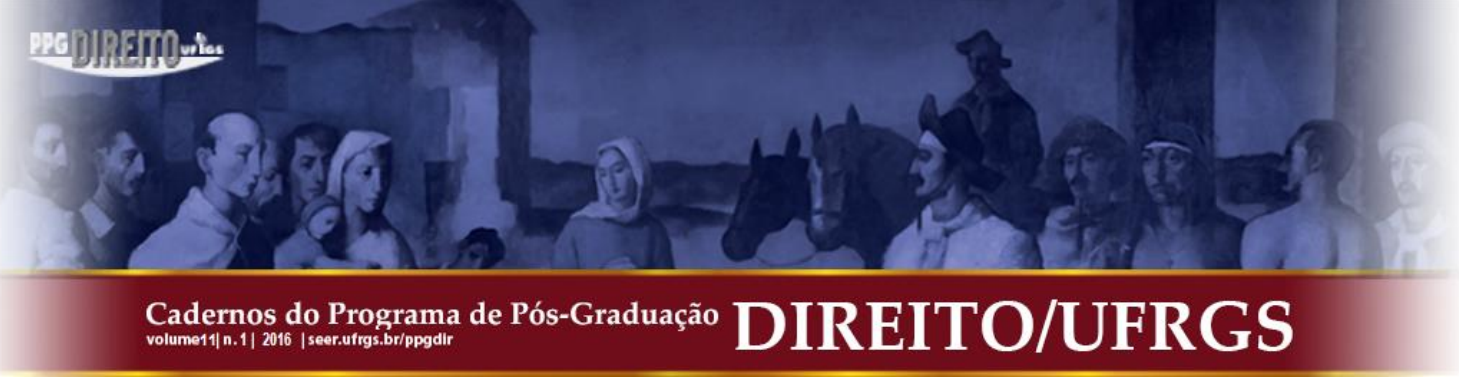

\subsubsection{Derrogação apenas internamente a uma ordem jurídica}

Normativamente, não se podem produzir efeitos internamente a uma ordem jurídica desde fora - por exemplo, a partir de uma outra ordem jurídica situada em um "sistema de múltiplos níveis”. Derrogação somente pode ocorrer entre normas pertencentes a uma mesma ordem jurídica. ${ }^{88}$ Isso é algo que se pode fundamentar por meio de um estudo de caso internamente ao direito nacional, onde também está em questão a relação entre ordens jurídicas (parciais): por meio da questão consistente em saber como o direito federal pode revogar uma norma de direito estadual. Direito federal e direito estadual constituem por si só, de qualquer maneira, um "sistema de dois níveis", com relação ao qual devem ser colocadas as mesmas questões estruturais que se colocam com relação a um sistema ampliado em um nível adicional "para cima". ${ }^{89}$

A primeira possibilidade segundo a qual uma norma de direito federal pode "afastar" uma norma de direito estadual consiste num recuo (em certo sentido espontâneo) desta última. ${ }^{90} \mathrm{O}$ direito estadual incorporaria o direito federal e não apresentaria pretensão de validade nos casos em que o direito federal viesse a contrariá-lo. Assim, o primado da validade do direto federal se deixaria esclarecer a partir do direito estadual: com recurso a uma "performance adaptativa [Anpassungsleistung] operativa unilateral" 91 do direito estadual. Esta performance adaptativa pode ser realizada de antemão por meio de uma incorporação dinâmica ou subsequentemente, por meio de um ato legislativo de direito estadual. ${ }^{92}$ Em ambos os casos, não ocorre uma aniquilação normativa do direito estadual por

\footnotetext{
${ }^{88}$ Do mesmo modo KELSEN, H. Derogation. In: NEWMAN R. A. (org.). Essays in Honour of R. Pound, 1962, p. 339 (p. 353); Idem, Zur Grundlegung der Völkerrechtslehre. Österreichische Zeitschrift für öffentliches Recht (ÖZöR). Nova Série n. 1, 1946/1948, p. 20 (p. 75).

${ }^{89}$ Uma disputa bastante semelhante às discussões acerca do direito europeu foi travada nos tempos do Império Germânico, onde especialmente Maximilian von Seydel defendia a primeira das construções aqui descritas; vgl. STOLLEIS, Michael. Geschichte des öffentlichen Rechts in Deutschland, Bd. 2, 1992, p. 288 e ss.

${ }^{90}$ De modo semelhante SAUER, Heiko. Grundrechtskollisionsrecht für das europäische Mehrebenensystem. In: MATZ-LÜCK, N.; HONG, M. (orgs.). Grundrechte und Grundfreiheiten im Mehrebenensystem - Konkurrenzen und Interferenzen, 2012, p. 1 (p. 31) fala em »evitar concorrências por meio de uma retração da vinculação [Bindungsrücknahme] $\ll$.

91 Expressão em: JESTAEDT, M. op. cit. (nota de rodapé 51), p. 661, aí com base na relação direito europeu/direito dos estados membros.

92 Para a relação paralela entre direito europeu e direito dos estados membros, despontam o caso do Tribunal Europeu, Rs. C-285/98, Tanja Kreil, Slg. 2000, I-95, ECLI:EU:C:2000:2, e a modificação do Art. 12a da Grundgesetz que se seguiu por meio da lei de 19.12.2000 (BGBl. I, 1755); este mesmo exemplo em JESTAEDT, M. op. cit. (nota de rodapé 51, acima), p. 654 e ss. Sobre "modificação legislativa formal condicionada pela integração como caso padrão” veja-se MAYER, F. C. op. cit. (nota de rodapé 52), p. 273.
} 


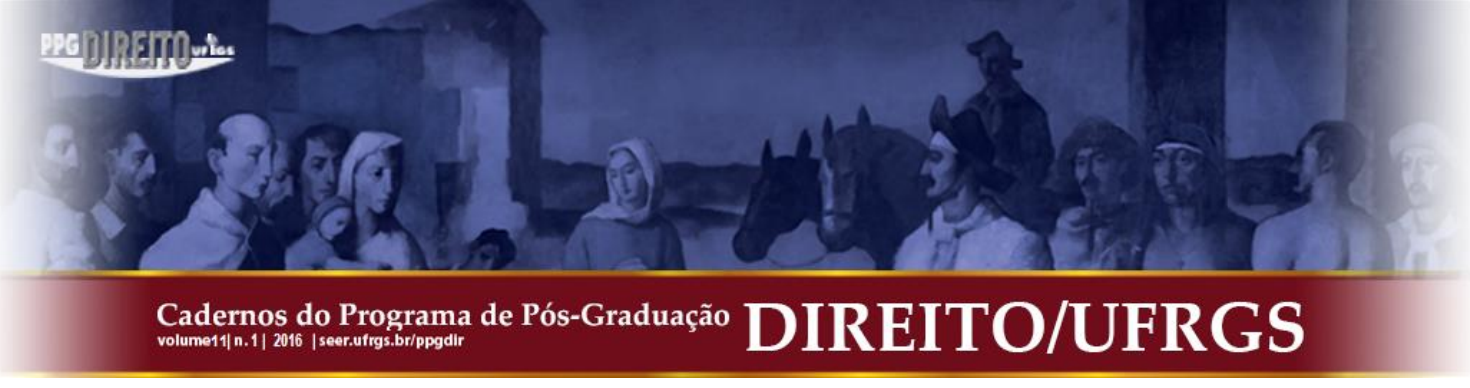

tomada como ponto de partida, por meio das quais a outra ordem jurídica possa ser “integrada", "encaixada". ${ }^{97}$ De outro modo, as duas ordens permaneceriam uma ao lado da outra, desconectadas. As ordens positivas que se têm em mente aqui dispõem de normas de atribuição de poder que podem ser compreendidas como tais pontos de conexão: assim, os direitos estaduais podem ser concebidos como delegações do direito federal, pela via dos artigos 30 e 70 da Grundgesetz, entre outros; o direito europeu poderia ser construído como uma delegação do direito alemão pela via do artigo 23 da Grundgesetz e, inversamente, o direito dos estados-membros poderia ser construído como delegação do direito europeu pela via do artigo $4^{\circ}$ do Tratado da União Europeia ${ }^{98}$ - em que se pode ler algo de semelhante ao art. 30 da Grundgesetz - e, se se quiser, mesmo as ordens nacionais podem ser construídas como delegadas por meio da alocação de autoridade pública (soberania) pela via do direito internacional público costumeiro. ${ }^{99}$

\subsubsection{Construção do direito internacional público e do direito europeu}

Diante deste pano de fundo, desde o ponto de vista de uma ciência normativa, direito internacional público e direito nacional, assim como direito europeu e direito dos estadosmembros, somente podem - se é que deve haver relações como "aplicação imediata" ou "primado de aplicação" do direito europeu entre eles ${ }^{100}$ - ser pensados como ordens parciais integrantes de uma ordem jurídica unitária. ${ }^{101}$ A aplicação do conceito de Estado da teoria do direito pode levar, aqui, a se considerar a estrutura da ordem jurídica de direito internacional

\footnotetext{
97 Veja-se JESTAEDT, M. op. cit. (nota de rodapé 51, acima), p. 659; KAMMERHOFER, J. op. cit. (nota de rodapé 82, acima), p. 241; WOODMAN, Gordon R. The Idea of Legal Pluralism. In: DUPRET, B.; BERGER, M.; AL-ZWAINI, L. (orgs.). Legal Pluralism in the Arab World, 1999, p. 3 (p. 18), fala em "reconhecimento normativo" [normative recognition]. Politicamente, isso pode ser interpretado como "responsividade" política da ordem jurídica: VIELLECHNER, Lars. Responsiver Rechtspluralismus. Der Staat. v. 51, 2012, p. 559.

${ }^{98}$ Veja-se, contudo, SCHROEDER, Werner. Das Gemeinschaftsrechtssystem, 2002, p. 250 e ss.

${ }^{99}$ Veja-se VERDROSS, A. op. cit. (nota de rodapé 79, acima), p. 35.

${ }^{100}$ S.a. GRILLER, S. op. cit. (nota de rodapé 95 , acima), p. 283; discutindo a »aplicação imediata« do direito internacional público ao direito europeu BOGDANDY, A. v. op. cit. (nota de rodapé 61, acima), p. 404-412.

${ }^{101}$ Sobre o direito internacional público KELSEN, H. Souveränität (nota de rodapé 19, acima), p. 123 e passim, igual JESTAEDT, Matthias (org.). Hans Kelsens Werke, v. 4, p. 385; sobre direito europeu JESTAEDT, M. op. cit. (nota de rodapé 51, acima), p. 667; SCHILLING, Thomas. Artikel 24 Absatz 1 des Grundgesetzes, Artikel 177 des EWG-Vertrags und die Einheit der Rechtsordnung. Der Staat. v. 29, 1990, p. 161 (p. 171 e ss, ver nota de rodapé 56); WAGNER, Heinz. Monismus und Dualismus. Archiv des öffentlichen Rechts (AöR). v. 89, 1964, p. 212 (p. 236). Não se pode colocar o direito válido em campo contra esta necessária assunção da teoria do direito; em sentido contrário, contudo KNAUFF, M. op. cit. (nota de rodapé 38, acima), p. 202.
} 


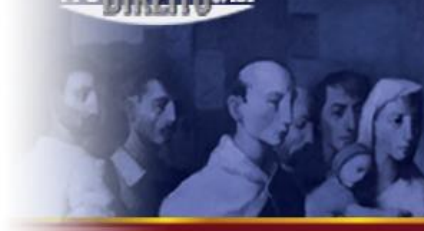

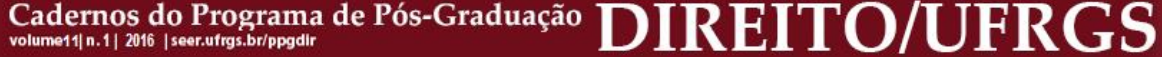

público como "Estado mundial" [Weltstaat] ${ }^{102}$ (organização de direito mundial) ${ }^{103}$; e a organização da ordem jurídica europeia, inclusive o direito dos estados-membros, como "estado federal"104 - sem que este conceito possa ser instrumentalizado politicamente, uma vez que aqui se trata de uma descrição teórica na perspectiva de uma ciência normativa. ${ }^{105} \mathrm{De}$ forma igualmente válida, contudo, a abordagem jurídica pode partir do direito nacional e reconduzir a ele a validade do direito europeu e do direito internacional público. ${ }^{106}$ A teoria do direito não tem condições de mitigar o corrente "limbo" político. ${ }^{107}$

\subsubsection{O caráter arbitrário da escolha do ponto de partida da abordagem jurídica}

Para a perspectiva científico-normativa, a escolha do ponto de referência a partir do qual a ordem jurídica será apresentada é arbitrária, porém determinante. O ponto de partida da abordagem determina a identidade da ordem jurídica observada e, com isso, do Estado, em sentido teórico-jurídico. Qual ponto de partida será escolhido, é, contudo, uma função dos respectivos fins a serem perseguidos ${ }^{108}$ - o que significará, no contexto das ciências, no mais das vezes: do poder explicativo da construção. ${ }^{109}$

102 KELSEN, H. Souveränität (nota de rodapé 19, acima), p. 249; igual JESTAEDT, Matthias (org.). Hans Kelsens Werke, v. 4, p. 507, em controvérsia com a "civitas máxima" de Christian Wolff.

${ }^{103}$ KELSEN, H. op. cit. (nota de rodapé 84, acima), p. 248.

${ }^{104}$ DREIER, H. op. cit. (nota de rodapé 1, acima), p. 104 com referências, designa, adequadamemte, »a questão da "forma do estado" (Estado, Confederação ou Federação de Estados) representada pela União Europeia, que de outro modo assumiria o primeiro plano, como improdutiva».

${ }^{105}$ Contrariamente à usurpação política da construção do direito internacional público por meio do "Primado do Direito Internacional Público" ou do "Primado do Direito Estatal", veja-se, principalmente KELSEN, H. op. cit. (nota de rodapé 84, acima), p. 244-246. Veja-se, ainda, a relação entre "Primado do Direito Internacional Público" e "Pacifismo" que Kelsen estabelece já em KELSEN, Hans. Souveränität (nota de rodapé 19, acima), p. 319, igual JESTAEDT, Matthias (org.). Hans Kelsens Werke, v. 4, p. 571.

${ }^{106}$ Veja-se, sobre o direito internacional público: KELSEN, H. op. cit. (nota de rodapé 84, acima), p. 246-248; sobre direito europeu JESTAEDT, M. op. cit. (nota de rodapé 51, acima), p. 668.

${ }^{107}$ Conceito em: WAHL, Rainer. Die Schwebelage im Verhältnis von Europäischer Union und Mitgliedstaaten. Der Staat. v. 48, 2009, p. 587.

108 Veja-se KELSEN, H. Reichsgesetz und Landesgesetz nach österreichischer Verfassung. Archiv fürs öffentliche Recht (AöR). v 32 (1914), p. 202 (p. 217); igual JESTAEDT, Matthias (org.). Hans Kelsens Werke, v. 3, p. 359 (p. 371); Idem. op. cit. (nota de rodapé 84, acima), p. 248; enquanto perspectiva, isso já se encontra em VERDROSS, A. op. cit. (nota de rodapé 85, acima), p. 337. A concatenação histórica dos fatos interpretados como atos de criação do direito é irrelevante para a construção jurídica [juristische Konstruktion], o que pode ser um tema a cada fundação de um Estado Federal ou Confederação de Estados; KELSEN, H. Souveränität (nota de rodapé 19, acima), p. 59; igual JESTAEDT, Matthias (org.). Hans Kelsens Werke, v. 4, p. 328; Idem. Reine Rechtslehre. 1. ed. (nota de rodapé 15, acima), p. 130; Idem. Reine Rechtslehre. 2. ed. (nota de rodapé 7, acima), p. 338; do mesmo modo VERDROSS, A. op. cit. (nota de rodapé 79, acima), p. 39 e ss.

${ }_{109}$ Veja-se. KELSEN, H. op. cit. (nota de rodapé 4, acima), p. 95 e ss.; VERDROSS, A. op. cit. (nota de rodapé 6, acima), p. 83.

Cadernos do Programa de Pós-Graduação em Direito PPGDir./UFRGS | Edição Digital | Porto Alegre | Volume XI | Número 1 | 2016 | P. 50-79 


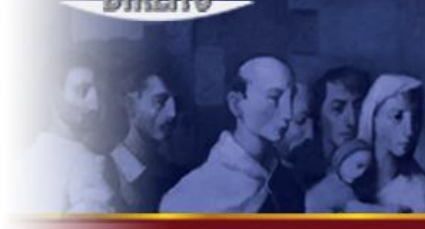

Cadernos do Programa de Pós-Graduação volume11| n.1| 2016 | seer.ufrgs.br/ppgdir

desvinculado do Estado, ${ }^{115}$ seria necessário escolher ainda outro ponto de partida - mesmo aqui, a adoção, por exemplo, dos estatutos de regulamentação das cortes arbitrais (destes quase-tribunais constituídos pela via contratual) ${ }^{116}$ como pontos de partida autorizaria uma construção teórico-jurídica com auxílio dos instrumentos pertinentes. ${ }^{117}$

Com a escolha do ponto de partida da abordagem jurídica ainda não se toma qualquer espécie de decisão preliminar sobre o conteúdo do direito. Quais as possibilidades de revogação existentes entre normas de distintas ordens jurídicas parciais de um sistema de múltiplos níveis ou de um sistema pluralístico concebidos como uma ordem jurídica coesa é uma questão que compete exclusivamente ao direito positivo. ${ }^{118}$ Aqui começa o campo da dogmática. A teoria do direito não pode resolver por si só a questão da precedência [de uma ordem jurídica sobre a outra]; ${ }^{119}$ contudo, um claro ponto de partida teórico-jurídico pode e deve orientar as disputas dogmáticas a serem travadas a este respeito.

\section{CONCLUSÃO - PERSPECTIVAS CIENTÍFICO-NORMATIVAS E CIENTÍFICO- SOCIAIS SOBRE A "TRANSFORMAÇÃO DO ESTADO"}

Fenômenos como o da autorregulação e o da "soft law" não possuem qualquer significado essencial para a estrutura da ordem jurídica - estes fenômenos se tornam interessantes, por outro lado, quando se assume uma perspectiva própria das ciências sociais. Para esta perspectiva autorregulação e "soft law" representam fatos tão brutos quanto aquelas ações humanas que a ciência normativa interpreta como atos de criação do direito. É possível ainda atribuir relevância científico-normativa à conversa sobre "sistemas de múltiplos níveis"

\footnotetext{
${ }^{115}$ Veja-se TEUBNER, G. op. cit. (nota de rodapé 69, acima).

${ }^{116}$ Expressão emprestada de TEUBNER, G. op. cit. (nota de rodapé 69, acima), p. 276.

117 O emprego distinto do símbolo operativo da "validade", que TEUBNER, G. op. cit. (nota de rodapé 66, acima), p. 211, observa como fato, corresponde, nesse sentido, à diferença entre distintos pontos de partida para a fundamentação da validade, diferença esta observável desde a perspectiva das ciências normativas.

118 Veja-se, por exemplo, VERDROSS, A. op. cit. (nota de rodapé 79, acima), p. 36 e ss; WIEDERIN, E. op. cit. (nota de rodapé 93, acima), p. 37 e ss. Esta característica da teoria atrai para ela a acusação de distanciamento da prática: ÖHLINGER, Theo. Die Einheit des Rechts. In: PAULSON, S. L.; STOLLEIS, M. (orgs.). Hans Kelsen, 2005, p. 160 (p. 173). Contudo, ela não pretende de modo algum solucionar os problemas da práxis jurídica - De modo diverso, contudo KELSEN, H. Souveränität (nota de rodapé 19, acima), p. 113, p. 146-149; igual JESTAEDT, Matthias (org.). Hans Kelsens Werke, v. 4, p. 377, p. 408-410.

${ }^{119}$ Nesse sentido, o âmbito de aplicação dos direitos fundamentais da Carta da União Europeia não se determina simplesmente "de modo definitivo segundo a norma fundamental do art. 23 da Grundgesetz", como assume SCHOLZ, Rupert. Nationale und europäische Grundrechte: Umgekehrte "Solange«-Regel? Deutsches Verwaltungsblatt (DVBl). v. 129, 2014, p. 197 (p. 202).
} 


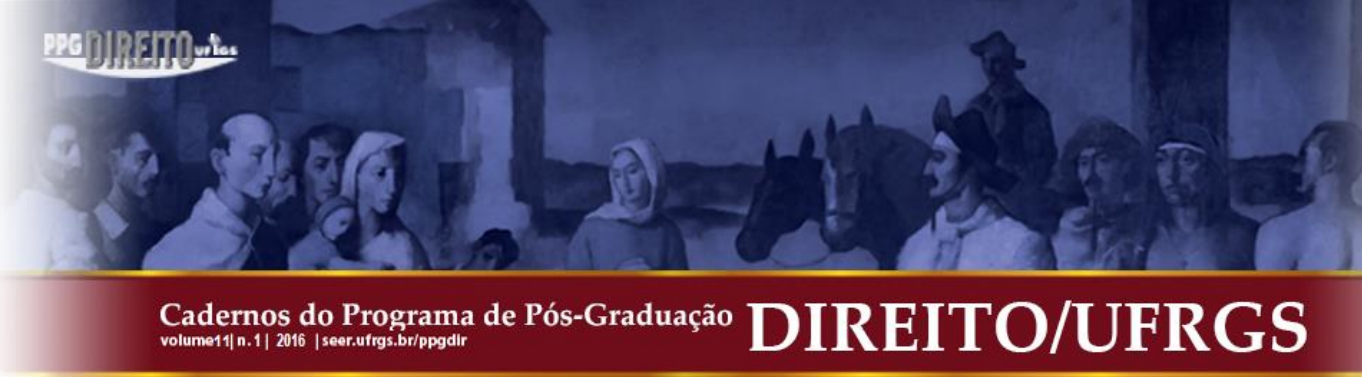

e "pluralismo jurídico". Aqui não se trataria apenas de uma transformação, mas sim eventualmente até mesmo de uma substituição da ordem jurídica [como um todo].

Com recurso ao instrumentário que remonta a Kelsen deixam-se descrever adequadamente, ainda hoje, os fundamentos teóricos necessários ao conhecimento jurídico. A teoria do direito pode, como ciência normativa, restar serena diante da "transformação do Estado" que tem sido recorrentemente vociferada contra ela, confiando a investigação dos fenômenos correlatos seguramente à sociologia e à história do direito.

\section{REFERÊNCIAS}

ALBERT, Hans-Peter. Der Staat als »Handlungssubjekt», 1988.

ARNDT, Dominik E. Sinn und Unsinn von Soft Law, 2011.

BERMAN, Paul Schiff. Global Legal Pluralism. Southern California Law Review. v. 80, 2007.

BOGDANDY, Armin von. Pluralism, direct effect, and the ultimate say. I.CON. v. 6, 2008.

BRUNNENGRÄBER, Achim; BURCHARDT, Hans-Jürgen; GÖRG, Christoph (orgs.). Mit mehr Ebenen mehr Gestaltung?, 2008.

CRAGG, Wesley. Multinational corporations, globalization and the challenge of selfregulation. In: KIRTON, J. J.; TREBILCOCK, M. J. (orgs.). Hard Choices, Soft Law, 2004.

DREIER, Horst. Hans Kelsens Wissenschaftsprogramm. In: SCHULZE-FIELITZ, Helmuth. (org.). Staatsrechtslehre als Wissenschaft, 2007.

EHRICKE, Ulrich. "Soft law» - Aspekte einer neuen Rechtsquelle. Neue Juristische Wochenschrift (NJW). v. 31, 1989.

FRERICHS, Sabine. Judicial Governance in der europäischen Rechtsgemeinschaft, 2008. 


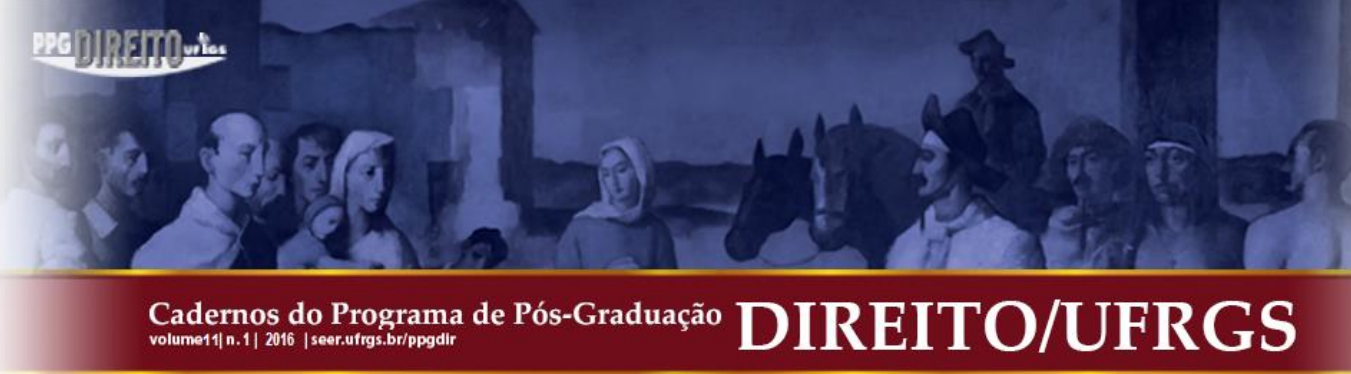

GOLDMANN, Matthias. We Need to Cut Off the Head of the King. Leiden Journal of International Law. v. 25, 2012.

GRILLER, Stefan. Der Stufenbau der österreichischen Rechtsordnung nach dem EU-Beitritt. Journal für Rechtspolitik (JRP). v. 8, 2000.

. Völkerrecht und Landesrecht. In: WALTER, R.; JABLONER, C.; ZELENY, K. (orgs.). Hans Kelsen und das Völkerrecht, 2004.

GÜNTHER, Klaus. Rechtspluralismus und universaler Code der Legalität. In: GÜNTHER, Klaus; WINGERT, Lutz. Die Öffentlichkeit der Vernunft und die Vernunft der Öffentlichkeit: Festschrift für Habermas, 2001.

HEUSEL, Wolfgang. »Weiches« Völkerrecht, 1989.

HOLUBEK, Reinhard. Allgemeine Staatslehre als empirische Wissenschaft, 1961.

HUMRICH, Christoph; ZANGL, Bernhard. Global governance through legislation. In: ENDERLEIN, H.; WÄLTI, S.; ZÜRN, M. (orgs.). Handbook on Multi-level Governance, 2010.

JABLONER, Clemens; OKRESEK, Wolf. Theoretische und praktische Anmerkungen zu Phänomenen des »soft law«. Österreichische Zeitschrift für öffentliches Recht. v. 34, 1983.

JELLINEK, Georg. Allgemeine Staatslehre. 3. ed., 1914.

JESTAEDT, Matthias. Der Europäische Verfassungsverbund. GS W. Blomeyer, 2004.

. Geltung des Systems und Geltung im System. Juristenzeitung (JZ). v. 68, 2013.

. Konkurrenz von Rechtsdeutungen statt Koexistenz von Rechtsordnungen. In: BRUNKHORST, H.; VOIGT, R. (orgs.). Rechts-Staat, 2008.

KAMMERHOFER, Jörg. Kelsen - Which Kelsen? A Reapplication of the Pure Theory to International Law. Leiden Journal of International Law. v. 22, 2009. 
KELSEN, Hans. Das Problem der Souveränität und die Theorie des Völkerrechts (1920). JESTAEDT, Matthias (org.). Hans Kelsens Werke. v. 4.

. Der soziologische und der juristische Staatsbegriff, 1922.

. Derogation. In: NEWMAN, R. A. (org.). Essays in Honour of R. Pound, 1962.

. Die Einheit von Völkerrecht und staatlichem Recht. Zeitschrift für ausländisches öffentliches Recht und Völkerrecht (ZaöRV). v. 19, 1958.

. Die soziologische und die juristische Staatsidee (1914). In: JESTAEDT, Matthias (org.). Hans Kelsens Werke. v. 3.

. General Theory of Law and State, 1945.

. Gott und Staat. Logos. v. 11, 1922/1923.

. Hauptprobleme der Staatsrechtslehre entwickelt aus der Lehre vom Rechtssatze, 1911. JESTAEDT, Matthias (org.). Hans Kelsens Werke. v. 2.

Les rapports de système entre le droit interne et le droit international public. Recueil des cours de l'Académie de droit international de La Haye. v. 14, 1926.

. Reichsgesetz und Landesgesetz nach österreichischer Verfassung. Archiv fürs öffentliche Recht (AöR). v. 32, 1914. JESTAEDT, Matthias (org.). Hans Kelsens Werke. v. 3.

. Reine Rechtslehre. 1. ed., 1934.

. Reine Rechtslehre. 2. ed., 1960.

. Staatsform als Rechtsform. Zeitschrift für öffentliches Recht. v. 5, 1926.

. Staat und Völkerrecht. Zeitschrift für öffentliches Recht. v. 4, 1925. 


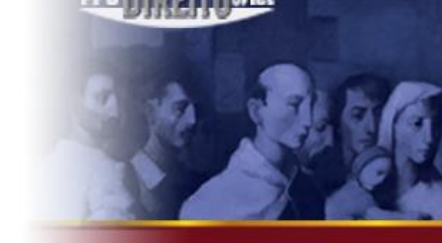

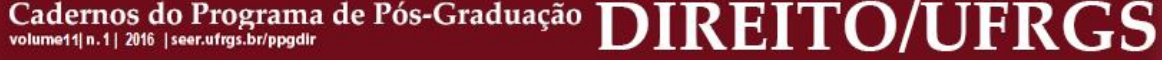

. Über Staatsunrecht. Grünhuts Zeitschrift. v. 40, 1914. JESTAEDT, Matthias (org.). Hans Kelsens Werke. v. 3.

. Was ist ein Rechtsakt? Österreichische Zeitschrift für öffentliches Recht. v. 4, 1952.

. Zur Grundlegung der Völkerrechtslehre. Österreichische Zeitschrift für öffentliches Recht (ÖZöR). Nova Série n. 1, 1946/1948.

KERSTEN, J. Georg Jellinek und die klassische Staatslehre, 2000.

KETTLER, Dietmar. Die Drei-Elemente-Lehre. Ein Beitrag zu Jellineks Staatsbegriff, seiner Fortführung Kritik, 1995.

KLABBERS, Jan. The Redundancy of Soft Law. Nordic Journal of International Law. v. 65, 1996.

KLEINLEIN, Thomas. Konstitutionalisierung im Völkerrecht, 2012.

KNAUFF, Matthias. Der Regelungsverbund, 2010.

KOCH, Hans-Joachim. Die staatsrechtliche Methode im Streit um die Zwei-Seiten-Theorie des Staates (Jellinek, Kelsen, Heller). In: PAULSON, Stanley L.; SCHULTE, Martin (orgs.). Georg Jellinek, 2000.

LAMPE, Ernst-Joachim. Vorwort. In: LAMPE, Ernst-Joachim (org.). Rechtsgleichheit und Rechtspluralismus, 1995.

LEPSIUS, Oliver. Die Zwei-Seiten-Lehre des Staates. In: ANTER, Andreas (org.). Die normative Kraft des Faktischen, 2004.

LEPSIUS, Oliver. Georg Jellineks Methodenlehre. In: PAULSON, S. L.; SCHULTE, M. (orgs.). Georg Jellinek.

LUHMANN, Niklas. Das Recht der Gesellschaft, 1993. 
. Die Politik der Gesellschaft, 2000

. Soziale Systeme, 1984.

LURGER, Brigitta. Der Pluralismus der >lex mercatoria<. Rechtshistorisches Journal. v. 16, 1997.

MAYER, Franz C. Verfassungswandel durch Annäherung? In: HÖNNIGE, Ch.; KNEIP, S.; LORENZ, A. (orgs.). Verfassungswandel im Mehrebenensystem, 2011.

MAYER, Hans. Reine Rechtslehre und Gemeinschaftsrecht. In: WALTER, R.; JABLONER, C.; ZELENY, K. Hans Kelsen und das Völkerrecht, 2004.

MELISSARIS, Emmanuel. Ubiquitous Law, 2009.

MERKL, Adolf Julius. Allgemeines Verwaltungsrecht, 1927.

MOORE, Sally Falk. Law as Process, 1978.

ÖHLINGER, Theo. Die Einheit des Rechts. In: PAULSON, S. L.; STOLLEIS, M. (orgs.). Hans Kelsen, 2005.

OOYEN, R. Ch. van. Der Staat der Moderne, 2003.

PIATTONI, Simona. The Theory of Multi-level Governance, 2010.

RÖHL, Klaus F.; MACHURA, Stefan. 100 Jahre Rechtssoziologie: Eugen Ehrlichs Rechtspluralismus heute. Juristenzeitung (JZ). v. 68, 2013.

SANDER, Fritz. Zeitschrift für öffentliches Recht. v. 1, 1919/1920. 


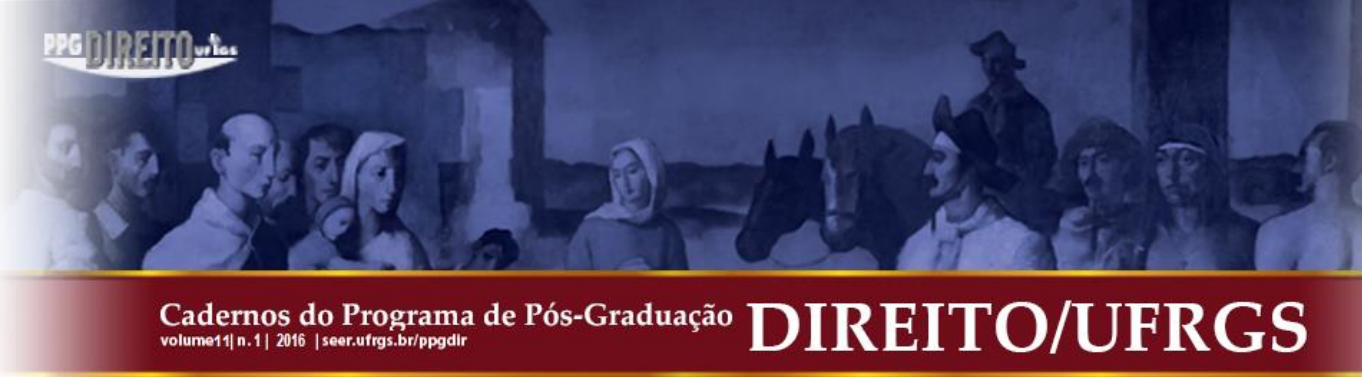

SAUER, Heiko. Grundrechtskollisionsrecht für das europäische Mehrebenensystem. In: MATZ-LÜCK, N.; HONG, M. (orgs.). Grundrechte und Grundfreiheiten im Mehrebenensystem - Konkurrenzen und Interferenzen, 2012.

SCHARF, Michael P.; ROBERTS, Lawrence D. The Interstellar Relations of the Federation: International Law and »Star Trek. The Next Generation«. University of Toledo Law Review. v. 25, 1994.

SCHILLING, Thomas. Artikel 24 Absatz 1 des Grundgesetzes, Artikel 177 des EWGVertrags und die Einheit der Rechtsordnung. Der Staat. v. 29, 1990.

SCHOLZ, Rupert. Nationale und europäische Grundrechte: Umgekehrte »Solange«-Regel? Deutsches Verwaltungsblatt (DVBl). v. 129, 2014.

SCHÖNBERGER, Christoph. Die Europäische Union als Bund. Archiv des öffentlichen Rechts (AöR). v. 129, 2004.

SCHROEDER, Werner. Das Gemeinschaftsrechtssystem, 2002.

SCHULZE-FIELITZ, Helmuth. Staatsrechtslehre als Wissenschaft. In: SCHULZE-FIELITZ, Helmuth. Staatsrechtslehre als Wissenschaft.

SCHWARZE, Jürgen. Soft Law im Recht der Europäischen Union. Europarecht (EuR). v. 46, 2011.

SECKELMANN, Margrit. Keine Alternative zur Staatlichkeit - Zum Konzept der »Global Governance«. Verwaltungsarchiv. v. 98, 2007.

SENDEN, Linda. Soft Law in European Community Law, 2004.

SOLTÈSZ, Ulrich. Europäisches »Soft Law« - Ein Wesen ohne Kuschelfaktor. Europäische Zeitschrift für Wirtschaftsrecht (EuZW). v. 24, 2013.

STOLLEIS, Michael. Geschichte des öffentlichen Rechts in Deutschland. Bd. 2, 1992.

TEUBNER, Gunther. Globale Bukowina. Rechtshistorisches Journal. v. 15, 1996. 
. Rechtspluralismus in der Spätmoderne. In: SCHMDIT, Eike et seq. (orgs.). Liber Amicorum J. Esser, 1995.

. Verfassungsfragmente, 2012.

TEUBNER, Gunther; KORTH, Peter. Zwei Arten des Rechtspluralismus. In: KÖTTER, M.; SCHUPPERT, G. F. (orgs.). Normative Pluralität ordnen, 2009.

TWINING, William. Globalisation and Legal Theory, 2000.

TYLER, Tom R. Why People Obey the Law, 2006.

VERDROSS, Alfred. Die Verfassung der Völkerrechtsgemeinschaft, 1926.

. Grundlagen und Grundlegungen des Völkerrechts. Niemeyers Zeitschrift für internationales Recht. v. 29, 1921.

. Zur Konstruktion des Völkerrechts. Zeitschrift für Völkerrecht. v. 8, 1914.

VIELLECHNER, Lars. Responsiver Rechtspluralismus. Der Staat. v. 51, 2012.

VOSSKUHLE, Andreas. Die Renaissance der »Allgemeinen Staatslehre« im Zeitalter der Europäisierung und Internationalisierung. JuS. v. 44, 2004.

WAGNER, Heinz. Monismus und Dualismus. Archiv des öffentlichen Rechts (AöR). v. 89, 1964.

WAHL, Rainer. Die Schwebelage im Verhältnis von Europäischer Union und Mitgliedstaaten. Der Staat. v. 482009.

WEIL, Prosper. Towards Relative Normativity in International Law? American Journal of International Law (AJIL). v. 77, 1983. 
WIEDERIN, Ewald. Bundesrecht und Landesrecht, 1995.

Die Stufenbaulehre Adolf Julius Merkls. In: GRILLER, S.; RILL, H. P. (orgs.). Rechtstheorie, 2011.

WOODMAN, Gordon R. The Idea of Legal Pluralism. In: DUPRET, B.; BERGER, M.; ALZWAINI, L. (orgs.). Legal Pluralism in the Arab World, 1999.

WÜRTENBERGER, Thomas. Rechtspluralismus oder Rechtsetatismus? In: E. J. Rechtsgleichheit und Rechtspluralismus, 1995.

ZÜRN, Michael; WÄLTI, Sonja; ENDERLEIN, Henrik. Introduction. In: ENDERLEIN, H.; WÄLTI, S.; ZÜRN, M. Handbook on Multi-level Governance, 2010.

Submissão: 20/07/2016

Aceito para Publicação: 20/07/2016 


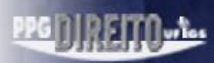

Cadernos do Programa de Pós-Graduação volume11| n.1| 2016 | seer.ufrgs.br/ppgditr

DIREITO/UFRGS 